\title{
The DtxR protein acting as dual transcriptional regulator directs a global regulatory network involved in iron metabolism of Corynebacterium glutamicum
} \author{
Iris Brune ${ }^{1,2}$, Hendrikje Werner ${ }^{1,2}$, Andrea T Hüser ${ }^{1}$, Jörn Kalinowski ${ }^{1}$,
} Alfred Pühler ${ }^{2}$ and Andreas Tauch*1

\author{
Address: ${ }^{1}$ Institut für Genomforschung, Centrum für Biotechnologie, Universität Bielefeld, Universitätsstraße 25, D-33615 Bielefeld, Germany and \\ ${ }^{2}$ Lehrstuhl für Genetik, Fakultät für Biologie, Universität Bielefeld, Universitätsstraße 25, D-33615 Bielefeld, Germany \\ Email: Iris Brune - Iris.Brune@Genetik.Uni-Bielefeld.DE; Hendrikje Werner - Hendrikje.Werner@Genetik.Uni-Bielefeld.DE; \\ Andrea T Hüser - Andrea.Hueser@Genetik.Uni-Bielefeld.DE; Jörn Kalinowski - Joern.Kalinowski@Genetik.Uni-Bielefeld.DE; \\ Alfred Pühler - puehler@Genetik.Uni-Bielefeld.DE; Andreas Tauch* - Andreas.Tauch@Genetik.Uni-Bielefeld.DE \\ * Corresponding author
}

Published: 09 February 2006

BMC Genomics 2006, 7:21 doi:10.1186/147|-2164-7-21

This article is available from: http://www.biomedcentral.com/I47|-2164/7/2I

(C) 2006 Brune et al; licensee BioMed Central Ltd.

This is an Open Access article distributed under the terms of the Creative Commons Attribution License (http://creativecommons.org/licenses/by/2.0), which permits unrestricted use, distribution, and reproduction in any medium, provided the original work is properly cited.
Received: 09 December 2005

Accepted: 09 February 2006

\begin{abstract}
Background: The knowledge about complete bacterial genome sequences opens the way to reconstruct the qualitative topology and global connectivity of transcriptional regulatory networks. Since iron is essential for a variety of cellular processes but also poses problems in biological systems due to its high toxicity, bacteria have evolved complex transcriptional regulatory networks to achieve an effective iron homeostasis. Here, we apply a combination of transcriptomics, bioinformatics, in vitro assays, and comparative genomics to decipher the regulatory network of the iron-dependent transcriptional regulator DtxR of Corynebacterium glutamicum.

Results: A deletion of the $d t x R$ gene of $C$. glutamicum ATCC 13032 led to the mutant strain $C$. glutamicum IB2 103 that was able to grow in minimal medium only under low-iron conditions. By performing genomewide DNA microarray hybridizations, differentially expressed genes involved in iron metabolism of $C$. glutamicum were detected in the $d t x R$ mutant. Bioinformatics analysis of the genome sequence identified a common 19-bp motif within the upstream region of 31 genes, whose differential expression in $C$. glutamicum IB2103 was verified by real-time reverse transcription PCR. Binding of a His-tagged DtxR protein to oligonucleotides containing the 19-bp motifs was demonstrated in vitro by DNA band shift assays. At least 64 genes encoding a variety of physiological functions in iron transport and utilization, in central carbohydrate metabolism and in transcriptional regulation are controlled directly by the DtxR protein. A comparison with the bioinformatically predicted networks of $C$. efficiens, $C$. diphtheriae and $C$. jeikeium identified evolutionary conserved elements of the DtxR network.

Conclusion: This work adds considerably to our currrent understanding of the transcriptional regulatory network of $C$. glutamicum genes that are controlled by DtxR. The DtxR protein has a major role in controlling the expression of genes involved in iron metabolism and exerts a dual regulatory function as repressor of genes participating in iron uptake and utilization and as activator of genes responsible for iron storage and DNA protection. The data suggest that the DtxR protein acts as global regulator by controlling the expression of other regulatory proteins that might take care of an iron-dependent regulation of a broader transcriptional network of $C$. glutamicum genes.
\end{abstract}




\section{Background}

One of the major challenges in post-genomic research is to decipher and reconstruct the complete connectivity of transcriptional regulatory networks encoded by a bacterial genome sequence $[1,2]$. The key components in regulation of bacterial gene expression are DNA-binding transcription factors that are able to sense changing environmental conditions and to modulate the expression of relevant target genes. An important prerequisite for understanding the regulation of gene expression in a bacterial cell in its entirety is the identification of the repertoire of regulatory proteins encoded by a genome sequence along with the complete set of genes that are under transcriptional control by each of the identified regulators $[3,4]$. The transcriptional network of the Gramnegative bacterium Escherichia coli is currently the bestunderstood regulatory system of a single cell. It includes 314 DNA-binding transcription factors and is characterized by a hierarchical and modular architecture that is composed of eight modules with distinct physiological functions. Even for this well-studied model organism, only a small fraction of the transcriptional regulatory interactions are currently known $[3,5]$.

The long-term objective of our post-genomic work is to characterize the complete repertoire of regulatory proteins of the Gram-positive bacterium Corynebacterium glutamicum along with the complete set of their target genes and corresponding DNA binding sites within the known genome sequence $[6,7]$. Since we also want to understand the evolution of the transcriptional regulatory network of C. glutamicum, we took advantage of the published genome sequences of Corynebacterium efficiens [8], Corynebacterium diphtheriae [9] and Corynebacterium jeikeium [10] to perform comparative genomic analyses. C. glutamicum and $C$. efficiens are widely used in biotechnological fermentation processes, whereas $C$. diphtheriae and $C$. jeikeium represent the most hazardous human pathogens among the corynebacteria. Therefore, the four species represent attractive targets to elucidate and compare not only the complete collection of DNA-binding transcriptional regulators but also the connectivity of regulatory interactions encoded by each genome sequence.

In a recent study, we have determined the complete sets of DNA-binding transcriptional regulators of the four corynebacteria and have performed a comparative content analysis of these genomes [7]. A collection of 127 DNA-binding transcriptional regulators was identified in the genome sequence of C. glutamicum, whereas 103 regulators were identified in C. efficiens, 63 in C. diphtheriae and 55 in $C$. jeikeium. The common set of transcriptional regulators encoded by the four corynebacterial genomes consists of only 28 proteins. Considering functional assignments deduced from computational predictions the common DNA-binding transcriptional regulators were grouped into five modules with distinct physiological functions [7]. The functional module "macroelement and metal homeostasis" includes, for instance, the transcriptional regulator $\mathrm{McbR}$, directing the global regulation of almost all aspects of sulphur metabolism, a FurB homolog, most likely involved in regulation of zinc metabolism [7], and a transcriptional regulator that is homologous to the diphtheria toxin repressor DtxR of $C$. diphtheriae [11]. The C. glutamicum DtxR protein shares $71 \%$ identical amino acid residues with the orthologous counterpart of C. diphtheriae.

The diphtheria toxin repressor DtxR has been shown to be a global transcriptional regulator of iron metabolism in $C$. diphtheriae [12]. Iron is essential for a variety of cellular processes in virtually all organisms, since it plays important roles as enzyme cofactor or as integral part of cytochromes in oxidation-reduction and energy-generating systems [13]. On the other hand, iron poses problems in biological systems since the oxidized form is poorly soluble and the reduced form is highly toxic. Therefore, bacteria have evolved various mechanisms to counter these problems and to achieve an effective iron homeostasis. In addition, expression of the iron homeostatic machinery is subject to iron-dependent transcriptional regulation, for instance of genes encoding high-affinity iron uptake systems, intracellular iron storage proteins, redox-stress resistance systems, and iron-containing proteins to control overall iron consumption of the cell [13]. In C. diphtheriae, almost 20 binding sites of DtxR have been identified either by targeted genetic experiments or by a global repressor titration assay [14,15]. Major physiological functions that are controlled by DtxR in response to the iron level include the expression of the diphtheria toxin [12], the synthesis and export of siderophores [14], the siderophore-dependent uptake of iron [16], and the synthesis of specific systems for the utilization of iron from heme, hemin and hemoglobin $[17,18]$.

In the present study, we have characterized the regulon of the transcriptional regulator DtxR of C. glutamicum by a genome-wide approach using DNA microarray technology. This global strategy along with bioinformatics predictions permitted the identification of DtxR binding sites in the C. glutamicum genome sequence along with a set of target genes that are under direct transcriptional control by DtxR. Binding of purified His-tagged DtxR protein to the upstream region of the respective genes was verified in vitro by DNA band shift assays. The resulting data were used for a comparative analysis of the deduced DtxR regulons in the four sequenced corynebacterial species. 


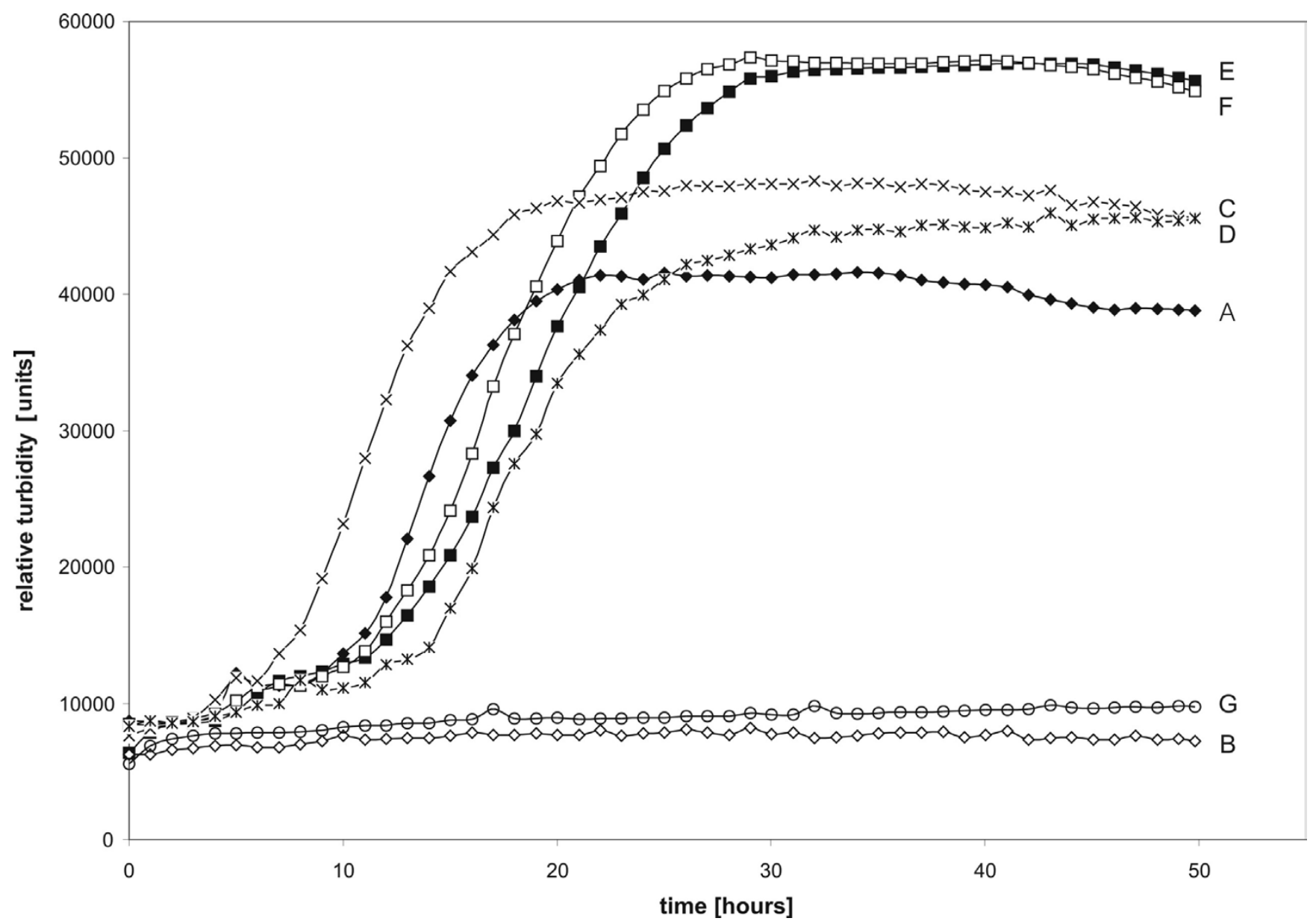

\section{Figure I}

Growth curves of the wild-type strain C. glutamicum ATCC 13032 and the dtxR mutant C. glutamicum IB2 I03. The strains and plasmid-carrying derivatives were cultivated in CGXII medium and in low-iron CGXII medium, respectively. Growth was monitored with a nephelometer and is shown as relative turbidity. Values are means of measurements of six biological replicates. Abbreviations: A, C. glutamicum ATCC 13032 in CGXII medium; B, C. glutamicum IB2 I03 in CGXII medium; C, C. glutamicum ATCC I3032 in low-iron CGXII medium; D, C. glutamicum IB2 I 03 in low-iron CGXII medium; E, C. glutamicum ATCC I3032 (plB4000) in CGXII medium; F, C. glutamicum IB2103 (pIB4000) in CGXII medium; G, C. glutamicum ATCC I3032 (pECXK99E) in CGXII medium.

\section{Results}

Phenotypic characterization of the dtxR mutant strain C. glutamicum IB2 I 03

The cg2103 (dtxR) gene of C. glutamicum ATCC 13032 encodes a transcriptional regulator with significant amino acid sequence similarity to the diphtheria toxin repressor DtxR of C. diphtheriae $[7,11]$. To explore the regulatory network controlled by the DtxR protein of C. glutamicum, a defined deletion was established in the coding region of $d t x R$ by applying a gene replacement strategy [19] that finally resulted in the mutant strain C. glutamicum IB2103. Subsequently, growth assays with C. glutamicum IB2103 were performed in liquid CGXII minimal medium and growth of the cultures was monitored by nephelometry (Figure 1). Growth assays with the wild-type strain $C$. glutamicum ATCC 13032 served as control. The growth assays clearly showed that C. glutamicum IB2103 containing the $d t x R$ gene deletion was unable to grow in CGXII minimal medium. On the other hand, the $d t x R$ mutant revealed the same growth characteristics as the wild-type strain when cultivated in low-iron CGXII medium (Figure 1). The growth deficiency of C. glutamicum IB2103 in CGXII minimal medium was complemented by transformation with plasmid pIB4000 carrying the cloned $d t x R$ gene. Control assays with C. glutamicum IB2103 containing the empty cloning vector pEC-XK99E failed to complement the phenotype of the mutant (Figure 1). These data demonstrate that the defined deletion of $d t x R$ in $C$. glutamicum IB2103 resulted in a conditionally lethal phenotype apparently depending on the amount of iron that 


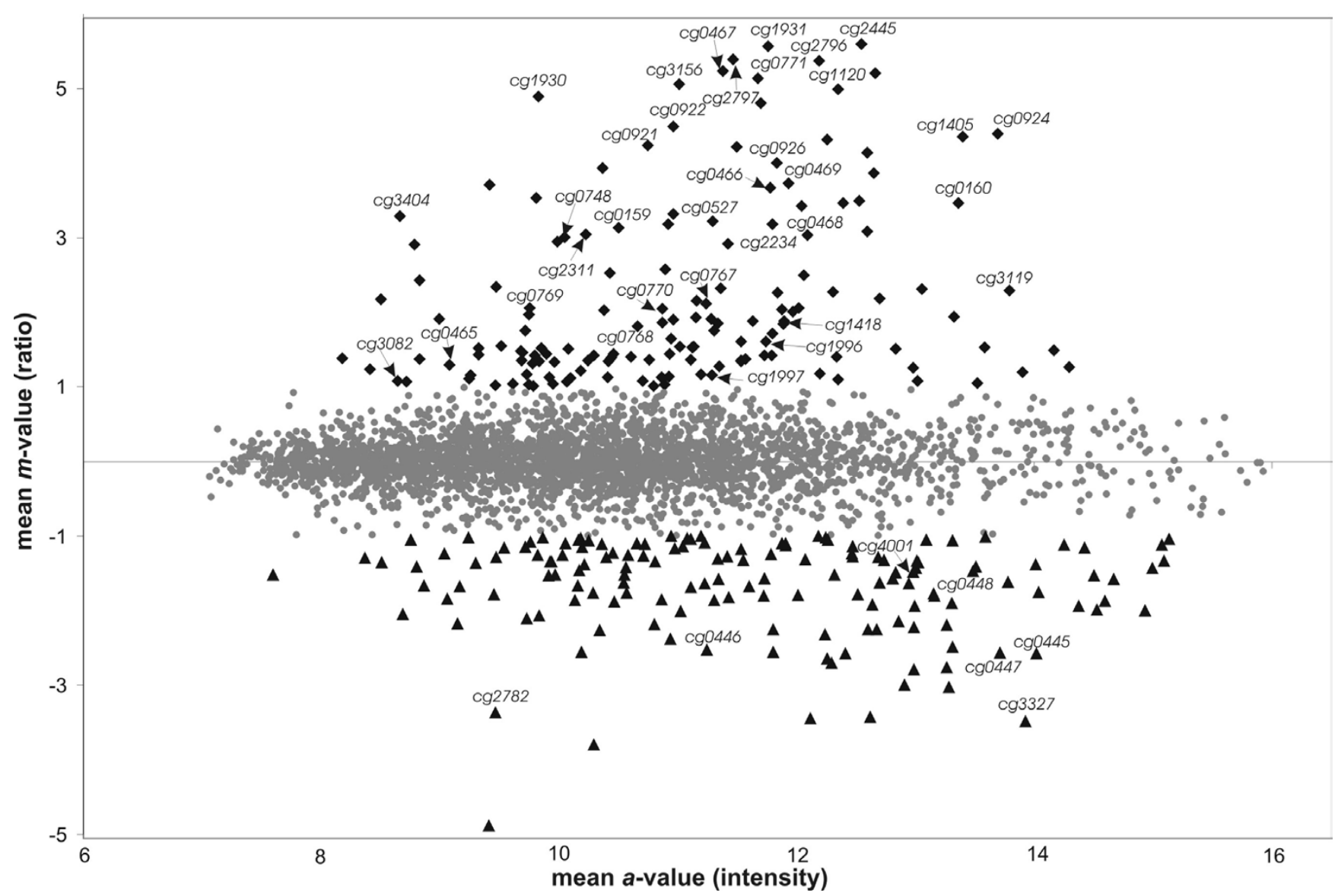

Figure 2

Ratio/intensity $(\mathrm{m} / \mathrm{a})$ plot deduced from DNA microarray hybridizations comparing the transcriptome of the $d t x R$ mutant $C$. glutamicum IB2 103 with that of the wild-type strain C. glutamicum ATCC 13032. The analyzed strains were cultivated in lowiron CGXII medium to mid-exponential growth phase. Then, $10 \mathrm{mg} / \mathrm{FeSO}_{4}$ was added to the medium, and the cultures were incubated for further $15 \mathrm{~min}$. Subsequently, total RNA was isolated from two biological replicates and used for DNA microarray hybridizations including label swapping. Genes showing enhanced expression in the dtxR mutant $C$. glutamicum IB2I03 are marked by black diamonds; genes with decreased expression are indicated by black triangles; genes without differential expression pattern are shown by gray spots. Differentially expressed genes later on assigned to the DtxR regulon of $C$. glutamicum are named by their identifiers. Genes were regarded as being differentially expressed with $a$-values equal or greater than 7.0 and $m$-values equal or greater than I (up-regulation) or equal or smaller than - I (down-regulation).

is supplied with the synthetic culture medium. This distinct phenotype of C. glutamicum IB2103 was suited to perform comparative transcriptomic studies with the wild-type strain to identify genes that belong to the transcriptional regulatory network of DtxR.

\section{Genome-wide transcriptional profiling of the dtxR mutant C. glutamicum IB2 103 in comparison to the wild-type strain ATCC 13032 by DNA microarray hybridization}

To identify genes that are differentially expressed in the transcriptome of C. glutamicum IB2103, the global gene expression pattern of the $d t x R$ mutant was compared with that of the wild-type strain by DNA microarray hybridization. Since C. glutamicum IB2103 was unable to grow in CGXII minimal medium (Figure 1), both strains were cul- tivated in shaking flasks to mid-exponential growth phase by using low-iron CGXII medium. The cultures revealed a very similar growth behavior that was characterized by almost identical doubling times of the $d t x R$ mutant $(4.8 \pm$ $0.41 \mathrm{~h})$ and the wild-type $(4.4 \pm 0.18 \mathrm{~h})$, indicating that differences in growth of both strains were apparently minimized under the selected cultivation conditions. At the time when the C. glutamicum strains were grown to an optical density of four $\left(\mathrm{OD}_{600 \mathrm{~nm}}\right), 10 \mathrm{mg} / \mathrm{l} \mathrm{FeSO}_{4}$ was added to the growth medium, and the cultures were cultivated for further $15 \mathrm{~min}$ before harvesting cells and preparing total RNA. Addition of iron to the wild-type culture should result in a "switch-off" of expression of those genes that are part of the DtxR regulon, whereas the respective genes should be further on expressed in the $d t x R$ mutant 
Table I: Identification of DtxR binding sites in the genome sequence of $C$. glutamicum

\begin{tabular}{|c|c|c|c|c|c|}
\hline \multirow[t]{2}{*}{ CDSI } & \multirow[t]{2}{*}{ Gene } & \multirow[t]{2}{*}{ Predicted DtxR binding motif ${ }^{2}$} & \multirow[t]{2}{*}{$\begin{array}{l}\text { Distance to translational } \\
\text { start codon }\end{array}$} & \multicolumn{2}{|c|}{$\begin{array}{c}\text { Differential gene expression in C. glutamicum IB2 I } 0 \\
\text { measured by }\end{array}$} \\
\hline & & & & $\begin{array}{l}\text { DNA microarray } \\
\quad(\text { ratio })^{4}\end{array}$ & $\begin{array}{l}\text { Real-time RT-PCR } \\
\text { (relative expression) }\end{array}$ \\
\hline $\operatorname{cg} 0466 *$ & - & TTAAGTTAGCATAGCCTTA & $|4|$ & +3.2 & +1160 \\
\hline $\operatorname{cg} 0748^{*}$ & - & ATAGGATAGGTTAACCTGA & 25 & +3.0 & +29 \\
\hline $\operatorname{cg} 077 I^{*}$ & - & GTCGGGCAGCCTAACCTAA & 40 & +5.3 & +239 \\
\hline $\operatorname{cg} 0922 *$ & - & TAAGGTTTGCCTAATCTTT & 30 & +4.4 & +176 \\
\hline $\operatorname{cg} 0924 *$ & - & TTAGGTAACCTAACCTCAC & 63 & +4.4 & +2000 \\
\hline $\operatorname{cg} 0926^{*}$ & - & TTAGGTTAGGCTCTAATAT & 173 & +4.0 & +185 \\
\hline $\operatorname{cg} / 405^{*}$ & - & TTTTGTTAGGCTTGCCTAG & 33 & +4.3 & +198 \\
\hline $\operatorname{cg} / 418^{*}$ & - & TTAGGTAAGGTTTGCATAC & 30 & +1.8 & +119 \\
\hline $\operatorname{cg} 2234 *$ & - & TTAGGCAAGGCTACCTTTT & 4 & +3.2 & +1980 \\
\hline $\operatorname{cg} 2445^{*}$ & hmuO & GTAGGTGTGGGTAACCTAA & 120 & +5.6 & +203 \\
\hline $\operatorname{cg} 2782 *$ & $f t n$ & TTATGCTGCGCTAACCTAT & 37 & -3.3 & +0.02 \\
\hline $\operatorname{cg} 3327^{*}$ & $d p s$ & TCAGGATAGGACAACCTAA & 61 & -3.4 & +0.01 \\
\hline $\operatorname{cg} 3404^{*}$ & - & TTAGGCTATCCTAACGCAA & overlap & +3.2 & +364 \\
\hline $\operatorname{cg} 0160$ & - & AATGGTTAGGCTAACCTTA & overlap & +3.4 & +1870 \\
\hline $\operatorname{cg} 0445$ & $s d h C D$ & TAAAGTAAGGCTATCCTAA & 111 & -2.5 & +0.12 \\
\hline $\operatorname{cg} 0527$ & - & TTAGGCTTGCCATACCTAT & 11 & +3.2 & +63 \\
\hline $\mathrm{cg} / / 20$ & ripA & TGAGGTTAGCGTAACCTAC & 32 & +4.9 & +359 \\
\hline cg/930 & - & TTAGGTAAAGCTTGCCTAT & 90 & +4.8 & +1210 \\
\hline cgl996 & cgllM & TTAGGATTCTCTCAACTAA & 199 & +1.7 & +3.8 \\
\hline $\operatorname{cg} 2311$ & - & TCAAGTAAGGTTTACCTTA & overlap & +3.0 & +37 \\
\hline cg2796 & - & GAAGGCAAGCCAAACTTAA & 18 & +5.3 & +1610 \\
\hline $\operatorname{cg} 3082$ & - & TTCTGTGAGGTTAACTTTT & 254 & +1.1 & +19 \\
\hline $\operatorname{cg} 3119$ & $f p r 2$ & TTAGGTTAGGTTCACCGTG & 204 & +2.2 & +18 \\
\hline $\operatorname{cg} 3156$ & - & TAAGGCAAGCCTAAATTAG & 97 & +5.0 & +304 \\
\hline $\operatorname{cg} 0405$ & - & TAAGGATAACCTTGCCTTA & 28 & n.d. & +1010 \\
\hline $\operatorname{cg} 0470$ & - & TTAGGTTAAGCTAATCTAG & 32 & n.d. & +978 \\
\hline $\operatorname{cg} 0591$ & - & TTAGTAAAGGCTCACCTAA & 91 & n.d. & +310 \\
\hline $\operatorname{cg} 0955$ & - & TTACGTGAGCGTAGCCGAA & 200 & n.d. & +2.8 \\
\hline cgl642 & - & TTAGGTTAGGCAAGCCATA & 39 & n.d. & +4.4 \\
\hline cg3247 & $\operatorname{cgt} R I I$ & ATCAGTAAGGCTAGACTAA & 87 & n.d. & +5.5 \\
\hline $\operatorname{cg} 3394$ & - & TTAAGGTAAGTTCAGCTAA & 37 & n.d. & +4.6 \\
\hline cg 1070 & - & ATAGGTTATCCAAGCCTAA & 18 & n.d. & n.d. \\
\hline $\operatorname{cg} 1088$ & - & TTAAGTCAGTGTTACCTAA & 82 & n.d. & n.d. \\
\hline $\operatorname{cg} 1966$ & - & TAACTTTGACATAACCTAA & 67 & n.d. & n.d. \\
\hline cg2224 & xerC & GTGTGTGAGGCAAGCCTAA & 93 & n.d. & n.d. \\
\hline cg2399 & $g l k$ & AAAGATTAAATTCACCTAA & 29 & n.d. & n.d. \\
\hline cg2598 & - & TTAGGTCAAGCTTGCATTT & 20 & n.d. & n.d. \\
\hline $\operatorname{cg} 2651$ & - & TTAGGTTGTAAAAACCTTA & 46 & n.d. & n.d. \\
\hline cg2842 & phou & TTAGGTGATTCAATCTTAA & 50 & n.d. & n.d. \\
\hline $\operatorname{cg} 3170$ & - & TTAACTTTGCCCTACCTAA & 190 & n.d. & n.d. \\
\hline
\end{tabular}

\footnotetext{
I Asterisks denote genes whose upstream regions were used for initial HMM processing.

${ }^{2}$ Bases belonging to predicted translational start codons are underlined.

${ }^{3}$ The distance from the last nucleotide of the DtxR binding site to the translational start codon is indicated.

${ }^{4}$ n.d., not detected as differentially expressed by using a significance cut-off of \pm I (ratio).

5 n.d.; not detected as differentially expressed by using a significance cut-off of +2 (up-regulation) or +0.5 (down-regulation).
}

C. glutamicum IB2103. Therefore, genes revealing an enhanced expression in C. glutamicum IB2103 when compared to the wild-type are candidates that might belong to the transcriptional regulatory network of DtxR.

Cell samples for total RNA preparation were taken from two independently grown C. glutamicum cultures of each strain. The respective RNA preparations were used in two DNA microarray hybridization assays by applying label swapping. Labeling of probes and DNA microarray hybridization were carried out as described previously [20]. To minimize the number of false-positive signals, the data were stringently filtered to obtain genes with at least six statistically significant values out of the eight 
technical replicates present on the two microarrays along with an error probability of less than 5\% for the Student's $t$-test. Normalization of the hybridization data by the LOWESS function and $t$-test statistics were accomplished by the EMMA software package. The resulting ratio/intensity $(\mathrm{m} / \mathrm{a})$ plot of the normalized data is presented in Figure 2 .

By applying a ratio cut-off of \pm 1 , corresponding to relative expression changes equal or greater than twofold, a total of 257 genes revealed a differential expression in $C$. glutamicum IB2103 (see Additional file 1). This number includes 131 genes with significantly increased expression in C. glutamicum IB2103 when compared to the wild-type strain ( $m$-value equal or greater than +1.0$)$ and 126 genes with decreased expression in the $d t x R$ mutant $(m$-value equal or smaller than -1.0). Several genes showing derepression of transcription in C. glutamicum IB2103 when compared to the wild-type strain encode iron-containing proteins and proteins that are apparently involved in iron transport and metabolism (Figure 2). Consequently, the upstream regions of the respective genes were ideally suited to search for the presence of a common DtxR binding motif.

\section{Computational identification of potential DtxR binding sites in the genome sequence of C. glutamicum ATCC 13032}

To identify DtxR binding sites in the genome sequence of C. glutamicum, the upstream regions of 13 differentially expressed genes encoding proteins involved in iron metabolism were selected (Table 1 ) and aligned by using the CLUSTAL X program [21]. The alignment identified a common 19-bp DNA motif with the palindromic consensus sequence 5'-TTAGGTTAG(G/C)CTAACCTAA-3' that is identical to DtxR binding sites identified earlier in C. diphtheriae [14]. A CLUSTAL X alignment of the 19-bp motifs was used to create a Hidden Markov model (HMM), and the C. glutamicum genome sequence was searched for the presence of additional motifs with this HMM profile. The results generated by HMM searches were then compared with the genomic positions of genes that showed differential expression in the $d t x R$ mutant C. glutamicum IB2103 during DNA microarray hybridization. This bioinformatics approach identified 24 motifs in front of genes that were identified as differentially expressed by DNA microarray hybridization, including the 13 motifs initially used as seed information to create the HMM profile (Table 1). It is noteworthy that three 19-bp motifs were predicted in front of genes (cg2782/ftn, cg3327/dps, cg0445/sdhCD) that showed a decreased expression in the $d t x R$ mutant $C$. glutamicum IB2103 (Table 1). The bioinformatics search identified additional 16 motifs upstream of genes that were not detected during the DNA microarray hybridization experiment. These motifs either represent false-posi- tive predictions or might be related to genes that were not detected with significant values during DNA microarray hybridization (see below). Accordingly, a total number of 40 potential DtxR binding sites was identified in the $C$. glutamicum genome sequence by bioinformatics analysis and further on investigated experimentally. Especially genes that showed an enhanced or decreased expression in the $d t x R$ mutant C. glutamicum IB2103 and that are moreover characterized by the presence of a predicted binding site within the corresponding upstream region can be considered as candidates for direct transcriptional regulation by DtxR.

\section{Verification of differential expression of genes with predicted Dtx $R$ binding sites by real-time RT-PCR experiments}

Differential expression of the 40 genes identified by bioinformatics screening of the C. glutamicum genome sequence for the presence of DtxR binding sites was examined further by real-time RT-PCR assays using the same experimental setup as applied for DNA microarray hybridizations. The resulting data are summarized in Table 1. The real-time RT-PCR assays demonstrated that the expression of 31 genes was enhanced up to 2000-fold in the $d t x R$ mutant C. glutamicum IB2103 when compared with the wild-type strain. Accordingly, the results can be divided into three categories: (i) Differential expression in C. glutamicum IB2103 of the 24 genes initially identified by the DNA microarray experiment was confirmed by the RT-PCR approach. (ii) Among the genes additionally predicted by HMM searches seven showed indeed a differential expression in the $d t x R$ mutant strain C. glutamicum IB2103. Expression of four genes was enhanced only up to 5 -fold, and a further examination of the DNA microarray data indicated that at least two of the respective ratios were close to the experimental cut-off (data not shown). (iii) In the case of nine potential motifs, the prediction by the HMM profile was most likely false-positive, since the corresponding genes showed no significant changes of the expression level in C. glutamicum IB2103, neither by DNA microarray hybridization nor by real-time RT-PCR measurements. Consequently, the combination of DNA microarray hybridization, bioinformatics screening approaches and real-time RT-PCR assays led to a set of genes that are differentially expressed in the $d t x R$ mutant C. glutamicum IB2103 and that are characterized by a putative DtxR binding site within the upstream region.

\section{Binding of purified DtxR protein to the identified sequence motifs as analyzed by DNA band shift assays}

To demonstrate binding of the DtxR regulator to the predicted 19-bp motifs by DNA band shift assays, a modified DtxR protein was constructed and subsequently purified. For this purpose, the coding region of the $d t x R$ gene was fused with a 3' extension encoding six histidine residues 
and amplified by PCR. The resulting DNA fragment was cloned in E. coli into the expression vector pEC-XK99E [22] resulting in plasmid pIB4001 that is suitable for heterologous overexpression of the modified DtxR protein upon IPTG induction. The His-tagged DtxR protein was purified to homogeneity from an induced $E$. coli culture by means of Ni-TED columns and positively identified by MALDI-TOF mass spectrometry and peptide mass fingerprinting (data not shown). Moreover, plasmid pIB4001 was transferred into the $d t x R$ mutant $C$. glutamicum IB2103 by electroporation to prove that the His-tagged DtxR protein is functional in vivo. This control experiment demonstrated that the growth deficiency of the $d t x R$ mutant C. glutamicum IB2103 in CGXII minimal medium can be complemented by plasmid pIB4001 but not by the empty cloning vector pEC-XK99E (data not shown).

Subsequently, DNA band shift assays were carried out with the purified His-tagged DtxR protein and distinct DNA fragments containing each of the 31 predicted 19-bp motifs. For this purpose, the motifs were extended on both sides with the respective gene-specific sequences to a total length of 40 nucleotides. These 40 mer oligonucoletides were labeled with $\mathrm{Cy} 3$ and annealed to produce double-stranded DNA fragments that were applied in band shift assays. First of all, 0.05 pmol of the labeled 40 mer DNA fragment representing the predicted DtxR binding site upstream of cg0771 was incubated with different amounts of His-tagged DtxR protein (42 pmol, $84 \mathrm{pmol}$, $126 \mathrm{pmol}, 168 \mathrm{pmol}$, and $210 \mathrm{pmol}$ ). The assays were then separated by agarose gel electrophoresis and visualized by fluorescence imaging (Figure 3A). Apparently, the presence of purified DtxR protein caused a different electrophoretic mobility of the labeled DNA fragment even at the low protein concentration of 42 pmol. Furthermore, DNA band shift assays were performed with labeled 40 mer control fragments located within the coding region of cg0397 and cg0738 (dnaE2), respectively. Incubation of purified DtxR protein with these DNA fragments delivered no band shift (Figure 3B). Binding of the DtxR protein to the upstream region of $c g 0771$ was also analyzed by DNA displacement experiments, in which increasing concentrations of the same non-labeled 40 mer fragment (0.015 to $1 \mathrm{pmol}$ ) were added to the band shift assay. Increasing concentrations of this sequence-specific competitor prevented the DNA band shift caused by the purified DtxR protein (Figure 3C). These data suggested a specific binding of the DtxR regulator to the upstream region of $c g 0771$ containing the common 19-bp motif.

Subsequent DNA band shift assays were performed with 42 pmol of purified DtxR protein (Figure 3D). The presence of purified DtxR protein caused a band shift of almost all tested 40 mer DNA fragments, with exception of a 40 mer region located in front of the $c g 1120$ gene that encodes the ArsR-type regulatory protein RipA [23]. The reason for this observation is currently unknown since binding of the DtxR protein to the upstream region of cg1120 was described earlier [23]. Nevertheless, the DNA band shift assays confirmed in vitro the binding of the DtxR regulator to specific DNA fragments containing the common 19-bp motif that was identified in the upstream region of differentially expressed genes.

\section{Localization of DtxR binding sites in mapped promoter regions of differentially expressed genes}

To determine the position of verified DtxR binding sites in relation to the promoter region of the respective genes, transcriptional start sites were identified by using the $5^{\prime}$ RACE method. Transcriptional starts were determined for the genes cg0771, cg0922 and cg0527 that showed an enhanced expression in the $d t x R$ mutant C. glutamicum IB2103 and for the $c g 2782, c g 3327$ and $c g 0445$ genes that revealed a decreased expression. The detected transcriptional start sites were identified in variable distances to the annotated translational starts of the corresponding proteins (Figure 4). The transcriptional start sites of cg0527, cg2782 and cg3327 were identical to the adenine residue of the annotated translational start codons. These results provided evidence for the presence of leaderless transcripts that are known to occur in C. glutamicum [24]. Moreover, the determination of transcriptional start points provided the basis for the identification of potential -35 and -10 promoter regions, according to the known features of corynebacterial promoter sequences [24]. At least three nuclotides of the potential - 35 and - 10 hexamers were identical to the consensus sequences TTGCCA and $\mathrm{TA}(\mathrm{C} / \mathrm{T}) \mathrm{AAT}$, respectively. In the case of cg0771, cg0922 and cg0527 the verified DtxR binding sites were located within the deduced promoter region (Figure 4), which is consistent with the physiological role of the DtxR protein as transcriptional repressor of gene expression. On the other hand, the DtxR binding sites of cg2782, cg3327 and $c g 0445$ were located upstream of the deduced -35 promoter regions (Figure 4). Since expression of these genes decreased in the $d t x R$ mutant C. glutamicum IB2103, as measured by DNA microarray hybridization and real-time RT-PCR, the location of the DtxR binding sites would be more consistent with an activating function of the DtxR protein [25].

\section{Bioinformatics characterization and functional dissection of the DtxR regulon of C. glutamicum}

The 31 genes, which were characterized by differential expression pattern in the $d t x R$ mutant $C$. glutamicum IB2 103 and by the presence of a DtxR binding site in front of the coding region, only represent a part of the DtxR regulon since operon structures also have to be considered. Therefore, the genetic organization of the respective gene regions was analyzed by using the annotation of the $C$. 
glutamicum genome sequence as visualized by the GenDB database system [6]. This genome annotation contains bioinformatics predictions of Rho-independent transcriptional terminators that were generated by the sofware tool TransTerm [26]. An inspection of the genome sequence for the presence of transcriptional terminators in the downstream regions of genes that are regulated by DtxR finally resulted in the identification of twelve gene clusters or operons (Figure 5). Taking these bioinformatics predictions into account along with the functional annotation of the differentially expressed genes, at least 64 genes appeared to be directly regulated by the DtxR protein. The respective genes and gene clusters of the C. glutamicum genome as well as DNA microarray hybridization data regarding the differential expression in the $d t x R$ mutant $C$. glutamicum IB2103 are shown in Figure 5.

The genes belonging to the DtxR regulon of C. glutamicum can be divided into seven functional categories (Figure 5) according to the predicted physiological roles of the deduced proteins [6]. The functional classification yielded a prominent group of 26 genes that encode iron transport systems or siderophore interacting proteins. Accordingly, this functional category includes almost half of the genes that are under direct transcriptional control by DtxR. Additionally, the genes cg2445 ( $\mathrm{hmuO}$ ), cg2782 (ftn) and cg3327 (dps) were identified as part of the DtxR regulon of C. glutamicum. The respective proteins specify the heme oxygenase $\mathrm{HmuO}$ involved in the release of iron from the heme moiety [27], a putative ferritin most likely involved in iron storage [13] and a Dps homolog that can act either in iron storage or as DNA-protecting anti-redox agent [13]. Expression of the $f t n$ and $d p s$ genes was decreased in the $d t x R$ mutant C. glutamicum IB2103 as was the expression of the $s d h$ gene cluster that encodes the components of the iron-containing succinate dehydrogenase complex of C. glutamicum [6]. The genes belonging to other categories of the DtxR regulon encode proteins without a precise functional prediction, secreted proteins of unknown function or even hypothetical proteins (Figure 5), with the exception of the $c g l$ gene cluster that represents the main DNA restriction and modification system of C. glutamicum ATCC 13032 [28] and the cysI-fpr2 gene region involved in assimilatory sulphate reduction [29].

Among the set of regulatory genes that are under direct control by DtxR, three DNA-binding transcriptional regulators were identified. This set includes the cg1120 (ripA) gene that was recently shown to be involved in iron metabolism of C. glutamicum [23] as well as the cg0527 and cg3082 genes encoding members of the ArsR family of regulatory proteins that typically exert metal-dependent transcriptional regulations in bacterial cells [7]. These data clearly indicate that the DtxR protein not only regulates the expression of genes playing a direct role in iron metabolism of C. glutamicum but also that of genes encoding transcriptional regulators, which can direct the expression of further target genes at another level of regulatory hierarchy.

Genome-wide identification of putative DtxR binding sites in corynebacterial genome sequences and comparative content analysis of the deduced DtxR regulons

Since genes encoding a DtxR homolog are highly conserved in corynebacteria [30], the deduced genetic and functional composition of the DtxR regulon of C. glutamicum was compared with DtxR regulons that were predicted by bioinformatics analysis of the genome sequences of C. efficiens [8], C. diphtheriae [9] and C. jeikeium [10]. A multiple nucleotide sequence alignment of the 31 verified 19-bp motifs of C. glutamicum provided the seed information to create a HMM profile that was used to search for the presence of DtxR binding sites in the corynebacterial genome sequences. The resulting hits were applied to generate species-specific HMMs, and the genome sequences were searched again for the presence of potential DtxR binding sites with the respective profiles. This iterative approach resulted in the prediction of 15 DtxR binding sites in the genome sequence of C. efficiens, whereas 27 DtxR binding sites were detected in the genome sequence of $C$. diphtheriae and 21 in that of $C$. jeikeium (Table 2). With respect to the genome annotations and the bioinformatics prediction of gene clusters at least 27 genes might be under direct transcriptional control by DtxR in C. efficiens, 59 in C. diphtheriae and 51 in C. jeikeium (Table 2).

Moreover, the identified 19-bp motifs were used to generate species-specific consensus sequences of the DtxR binding sites by means of the WebLogo tool [31]. The resulting sequence logos are shown in Figure 6A. The overall height of each stack of letters indicates the sequence conservation at each position of the 19-bp motif, wheras the heigth of each symbol within the stack reflects the relative frequency of the corresponding nucleotide at that position. A comparison of the sequence logos clearly indicated that the four 19-bp motifs resemble the overall palindromic consensus sequence 5'-TTAGGTTAG(G/C)CTAACCTAA3' of DtxR binding sites, with apparent species-specific variations (Figure 6A). Accordingly, the sequenced corynebacterial genomes not only encode a conserved DtxR homolog but also contain sets of similar 19-bp motifs that represent potential DtxR binding sites. These data along with the verified DtxR binding sites of $C$. glutamicum and the annotated genome sequences of $C$. efficiens, C. diphtheriae and C. jeikeium enabled us to analyze and compare the genetic composition of the DtxR regulons in these corynebacterial species. 

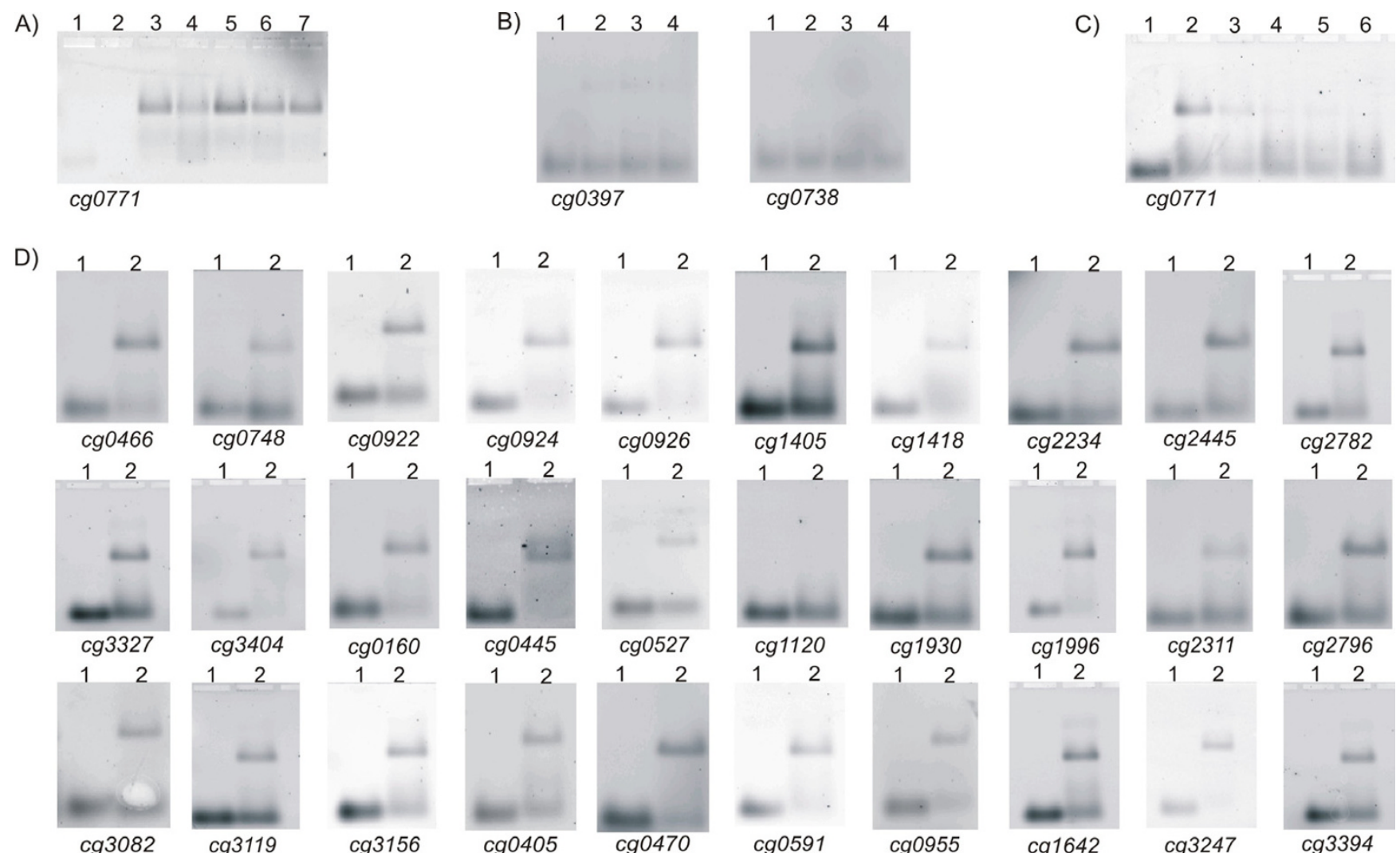

$\operatorname{cg} 0405$

$\operatorname{cg} 0470$
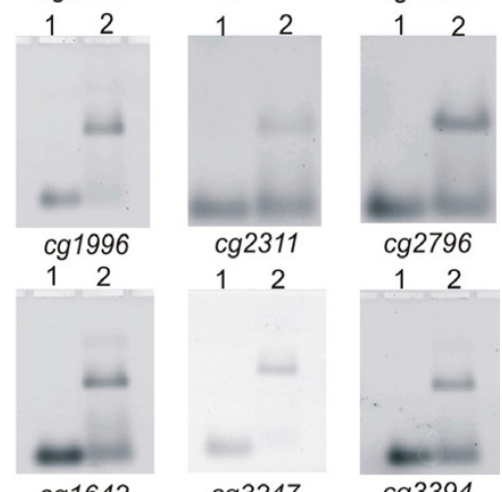

Figure 3

Agarose gels of DNA band shift assays performed with purified His-tagged DtxR protein. (A) DNA band shift assays with a Cy3-labeled double-stranded 40 mer covering the predicted DtxR binding sites in front of the cg077I gene. Band shifts were performed with 0.05 pmol of the labeled 40 mer DNA fragment and different amounts of the His-tagged DtxR protein. Assays were separated in a $2 \%$ agarose gel and visualized by fluorescence imaging. Lane I: control assay without DtxR protein; lane 2 : control assay without 40 mer; lane 3: band shift assay with 42 pmol DtxR; lane 4: assay with 84 pmol DtxR; lane 5: assay with 126 pmol DtxR; lane 6: assay with 168 pmol DtxR; lane 7: assay with 210 pmol DtxR. (B) Control experiments with Cy3labeled 40 mers deduced from internal gene regions of cg0397 and cg0738 (dnaE2). Lanes I: control assay without DtxR protein; lanes 2: control assay containing 42 pmol DtxR protein; lanes 3: assays with 84 pmol DtxR; lanes 4: assays with I 26 pmol DtxR. (C) DNA displacement experiments with a Cy3-labeled double-stranded 40 mer covering the predicted DtxR binding sites in front of the $\mathrm{cg} 077 \mathrm{I}$ gene. During displacement studies, $42 \mathrm{pmol}$ of purified His-tagged DtxR protein and $0.05 \mathrm{pmol}$ of a Cy3-labeled 40 mer along with increasing concentrations of the same non-labeled 40 mer fragment were added to assay. Lane I: control assay without purified DtxR protein; lane 2: control assay without non-labeled 40 mer; lane 3: assay with 0.0 I 5 pmol non-labeled 40 mer; lane 4: assay with 0.3 pmol non-labeled 40 mer; lane 5: assay with 0.45 pmol non-labeled 40 mer; lane 6: assay with I pmol non-labeled 40 mer. (D) Verification of the predicted DtxR binding sites by DNA band shift assays using 0.05 pmol of Cy3-labeled 40 mers and 42 pmol of purified His-tagged DtxR protein. Gene identifiers are shown below the agarose gels. Lanes I: control assay without DtxR protein; lanes 2: DNA band shift assay containing DtxR protein.

To identify either species-specific or common genes that are under transcriptional control by DtxR in corynebacteria, functional predictions of the coding regions located downstream of the determined DtxR binding sites were compared between the four sequenced species. Orthologous proteins were identified within the complete collection of potentially DtxR-regulated genes by using the BLASTP algorithm [32] to detect amino acid sequence similarities and by performing synteny analyses of the respective genomic context. The resulting data were visualized as Venn diagrams (Figure 6B). First of all, it is apparent that the four corynebacteria share no common gene that is under direct transcriptional control by the DtxR regulator. This unexpected result might be due to the exceptional collection of species-specific genes that are involved in iron metabolism of C. jeikeium [10]. The set of 


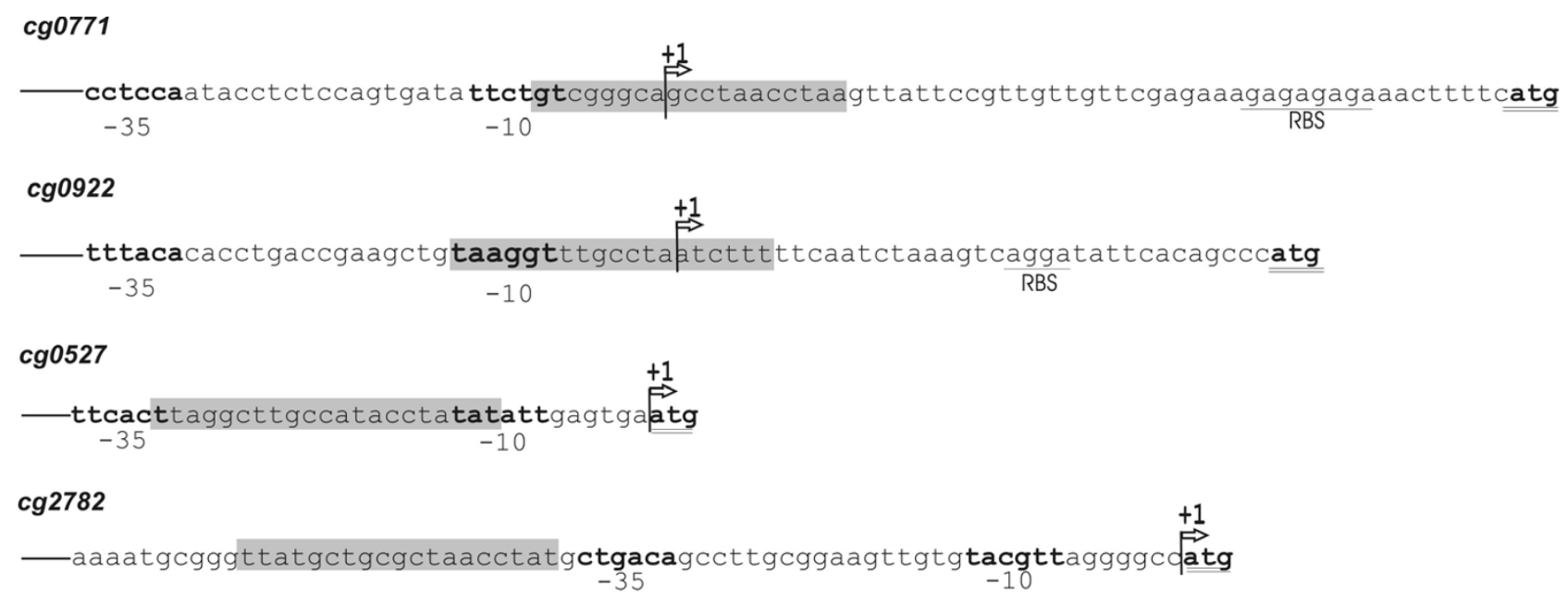

$\operatorname{cg} 3327$

- cactttcaggataggacaacctaatataaataagcttaggctaagggccggtgacaatttatcaagcagtgctataataataggggtcatg

$\operatorname{cg} 0445$

-atgagcgtcaaacgacaataaagtaaggctatcctaataagtggggttttatgtctctaaacagccagttgggggtcat RipA binding site $\mathrm{A}$

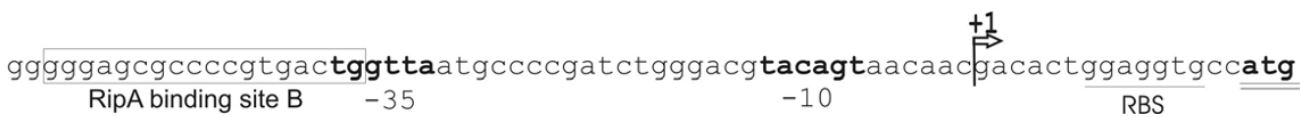

Figure 4

Detailed genetic maps of upstream regions of selected genes belonging to the DtxR regulon of $C$. glutamicum. The nucleotide sequences shown indicate the DtxR binding sites (gray boxes) and the identified transcriptional start sites that were mapped with the RACE method (+I). Bold-faced nucleotides display deduced -35 and -10 hexamer sequences of corynebacterial promoter regions. Potential ribosome-binding sites (RBS) in front of the coding regions are underlined; the ATG start codon is double underlined. The cg0527, cg2782 and cg3327 genes are expressed by leaderless transcripts. Previously identified RipA binding sites in front of the cg0445 genes are marked [23].

orthologous genes that are most likely under transcriptional regulation by DtxR in three corynebacterial species includes the orthologs of the cg0466 gene cluster (Figure 5) that encode components of an iron ABC transport system in C. glutamicum, C. diphtheriae and C. jeikeium and the orthologs of the cg0926 gene cluster that are apparently involved in iron uptake in C. glutamicum, C. efficiens and $C$. jeikeium. Orthologs of the $s d h$ gene cluster and the $f t n$ gene, whose expression decreased in the $d t x R$ mutant C. glutamicum IB2103, are apparently under direct transcriptional control by DtxR in C. efficiens and C. diphtheriae, indicating that the DtxR regulator might be involved in the activation of gene expression also in these species. Regulatory genes orthologous with cg0527 of C. glutamicum are present in the genomes of C. efficiens and C. diphtheriae [7] and all are presumably regulated by DtxR, suggesting similar hierarchical topologies of the respective DtxR regulons. However, most of the identified genes that are under transcriptional control by DtxR are species-spe- cific, although one has to keep in mind that some nonorthologous genes might share similar physiological functions. This comparative content analysis led to the conclusion that the DtxR regulons of corynebacteria are quite different in their genetic composition, although they rely on an orthologous regulatory protein and similar 19-bp motifs for regulator binding. Nevertheless, some interesting regulatory features deduced from the experimental characterization of the DtxR regulon of C. glutamicum are apparently realized also in the topology of DtxR regulons of other corynebacteria.

\section{Discussion}

In the present study, the genetic network of the transcriptional regulator DtxR was examined in C. glutamicum, and the topology of the DtxR regulon was deduced from DNA microarray hybridizations, bioinformatics approaches, in vivo studies of differential gene expression, and DNA band shift assays. For these purposes, a defined deletion was 
A) Iron transport systems and siderophore interacting proteins (26 genes)
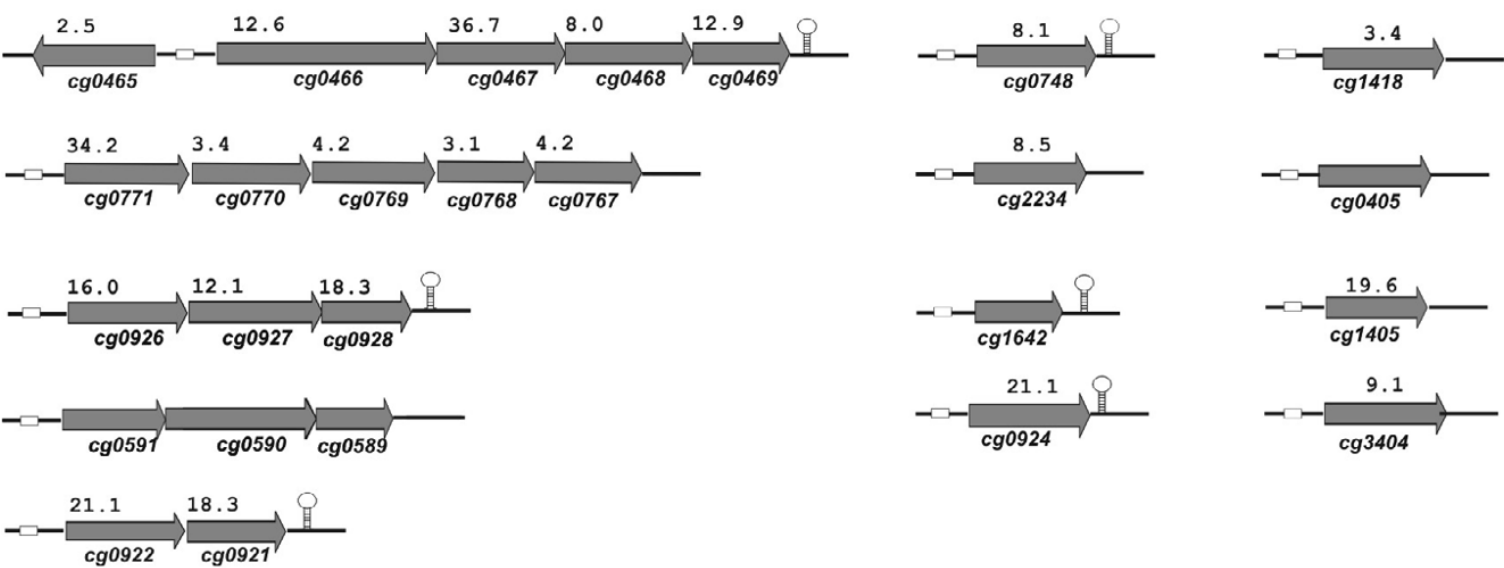

B) Central metabolism (5 genes)

C) Iron utilization, storage and protection (3 genes)
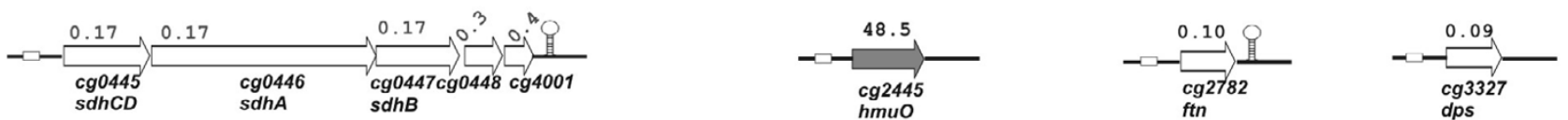

D) Secreted proteins (7 genes)

$-\left.\underbrace{27.8}_{c g 1930}\right|_{c g 1931} ^{45.2}$
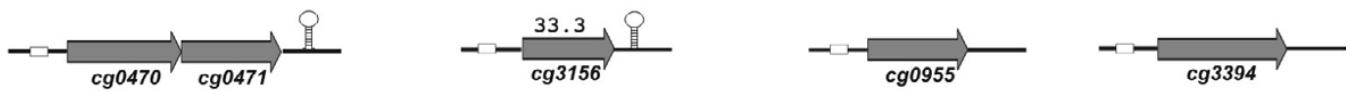

E) Methylases, methyltransferases and reductases (12 genes)
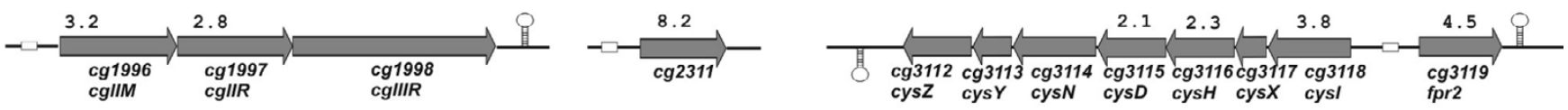

F) Regulatory proteins (7 genes)
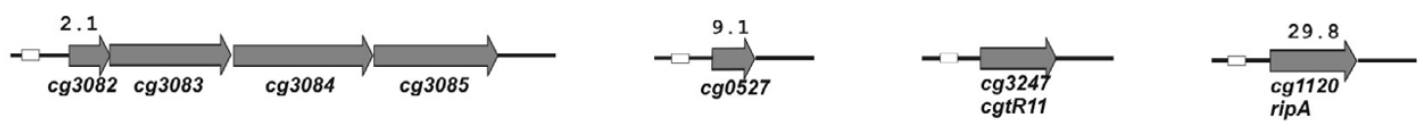

G) Hypothetical proteins (4 genes)

$\underbrace{c}_{c g 0160} \underbrace{10.5}_{c g 0159}$

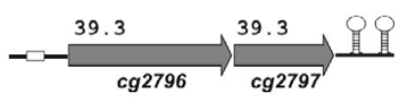

\section{Figure 5}

Functional dissection of genes belonging to the DtxR regulon of $C$. glutamicum. Genes and gene clusters showing differential expression in the $d t x R$ mutant $C$. glutamicum IB2 103 are presented. The respective values of differential gene expression shown above the arrows were deduced from DNA microarray hybridizations. Genes with decreased expression in $C$. glutamicum IB2 I03 are shown as white arrows; genes without a given value were detected only by real-time RT-PCR (Table I). Predicted Rho-independent transcriptional terminators are indicated by hairpin structures, DtxR binding sites by white boxes. The DtxR binding site in front of cg0466 and cg3/19 might also be involved in regulation of expression of genes on the opposite DNA strand [14]. The identified genes were grouped into seven functional classes (A-G) according to proposed physiological functions of the encoded proteins. 
Table 2: Predicted DtxR binding sites in corynebacterial genome sequences

\begin{tabular}{|c|c|c|c|c|}
\hline CDS & Predicted DtxR binding site & Clustered with & Predicted function & Orthologs \\
\hline \multicolumn{5}{|c|}{ Corynebacterium diphtheriae } \\
\hline DIP0I08I & TTTTCTTTGCCTAGCCTAA & DIPOI09-0II0 & iron $A B C$ transport system & JK066I \\
\hline DIPOI24I & TTAGGGAACTCTTGCCTTA & - & membrane protein & - \\
\hline DIP0I69 & TTAGCTTAGCCCTAGCTAA & - & secreted protein & - \\
\hline DIP0222' & TTAGGATAGCTTTACCTAA & - & diphtheria toxin precursor & - \\
\hline DIP0370 & TTAGGTCAGGGTACCCTAA & DIP037I-0373 & succinate dehydrogenase complex & cg0445, CE0386 \\
\hline DIP04I5 & TTAGCTTAACCTTGCCTAT & - & ArsR-family regulatory protein & cg0527, CE0466 \\
\hline DIP0540I & CTAGGTTAGGGGTGCCTAA & DIP054I & preprotein translocase subunit $\mathrm{Sec} Y$ & - \\
\hline DIP0579 & TTAGGCGACGGTTGCCTCA & - & hypothetical protein & - \\
\hline DIP0582। & TTAGGGTTGTGTTACCTTG & DIP0583-0585 & iron $A B C$ transport system & - \\
\hline DIP05861 & TTAGGGTAGCTTCGCCTAA & DIP0587-0588 & siderophore biosynthesis protein & - \\
\hline DIP0625I & TTAGGTAAGTGTAGCCTAT & DIP0624-06293 & iron $A B C$ transport system & $\operatorname{cg} 0466, J K 0315$ \\
\hline DIP0699 & TTGTGTTAGCCTAGGCTAA & - & preprotein translocase subunit $\operatorname{Sec} A$ & - \\
\hline DIP0894! & CTAGGATTGCCTACACTTA & - & hypothetical protein & CEI009 \\
\hline DIP09221 & TAACCTTAGGCTTGCCTTT & - & AraC-family regulatory protein & $\mathrm{cg} / / 20$ \\
\hline DIPI06II & TTAGGGTAACCTGTCCAAC & DIPI062-10593 & iron $A B C$ transport system & - \\
\hline DIPII90 & ATGGGGGAGGCTCACATAA & - & peptide transport protein & - \\
\hline DIPI2961 & TTAGGGTGGGCTAACCTGC & DIPI295-1290 & DNA binding protein & JK0985 \\
\hline DIPI520I & TTAGGTTAACCTTGCTTAA & DIPI5I9 & membrane proteins & - \\
\hline DIPI626 & TGATGGAAACCACCCCTAA & DIPI625-1624 & ubiquinol-cytochrome $C$ reductase & - \\
\hline DIPI669I & TGAGGGGAACCTAACCTAA & - & heme oxygenase & $\operatorname{cg} 2445$ \\
\hline DIPI 866 & TTATGCTGGGCTATCTTAA & - & bacterioferritin-like protein & cg2782, CE2420 \\
\hline DIP2I|4| & AAAGGTAAGCCATAGCTAA & - & alcohol dehydrogenase & - \\
\hline DIP2I6II & TTGGATTAGCCTACCCTAA & DIP2I58-2160 & non-ribosomal peptide synthase & - \\
\hline DIP2202 & TGAAGGTACCCCAGCCTAA & - & choline dehydrogenase & - \\
\hline DIP2219 & CTGGGGAACCGTTACCTAA & DIP2220 & hypothetical proteins & - \\
\hline DIP2303 & TAAGGATAGGCCACCCCAA & - & Dps protein & $\operatorname{cg} 3327$ \\
\hline DIP2330 & ATAGGCATGCCTAACCTCA & - & membrane protein & - \\
\hline
\end{tabular}

Corynebacterium efficiens

\begin{tabular}{|c|c|c|c|c|}
\hline CEOI 25 & TTAGGCTAACCTTGCCCAA & - & hypothetical protein & $\operatorname{cg} 0160$ \\
\hline CE0386 & CGAGGTGAGGCTAGCCTAA & CE0387-0389 & succinate dehydrogenase complex & cg0445, DIP0370 \\
\hline CE0466 & ATAGCTTAGGCTTACCTGC & - & ArsR-family regulatory protein & cg0527, DIP04I5 \\
\hline CE0687 & GTTGGACACCCTAACCTAA & CE0683-0686 & iron $A B C$ transport system & $\operatorname{cg} 0771$ \\
\hline CE088I & TTAGGTACCCTAACCTCAC & CE0882-0884 & iron $A B C$ transport system & cg0926, JK 1887 \\
\hline CE0912 & GTAGGTTACGCGAACGTAG & - & hypothetical protein & $\operatorname{cg} 0955$ \\
\hline CEI009 & TTAGGCATCCCTTGCCTCG & CEIOIO & hypothetical proteins & DIP0894 \\
\hline CEI346 & AGAGTGTAGGCTTACCTAT & - & hypothetical protein & $\mathrm{cg} / 405$ \\
\hline CEI860 & TTAGGTTATAGTTTCCTTT & CEI859 & hypothetical proteins & - \\
\hline CEI917 & GTGGGTGAGGCAAGCCTAA & - & phage integrase/recombinase & - \\
\hline CEI940 & TGAAGTAACACTACCCTAA & - & cation transporting P-type ATPase & - \\
\hline CE2420 & TTATGGTGCGCTAACCTTG & - & ferritin-like protein & cg2782, DIPI 866 \\
\hline CE2790 & TCAGGAAAGGTTAGCCCAA & - & hypothetical protein & - \\
\hline CE28I5 & CTATGTTTGGCAAGCCTTA & - & hypothetical protein & - \\
\hline CE289। & CTGGGCTAGGGTCACCTAT & - & hypothetical protein & - \\
\hline
\end{tabular}

Corynebacterium jeikeium

\begin{tabular}{lll}
\hline JK0030 & TTCTTTCAGGCTAACCTAT & - \\
JK03I4 & TTAGGTAAGGCTCGACTTA & - \\
JK03I5 & TAAGGTAACACTATCCTAA & JK03I6-03I9 \\
JK0434 & TTAGGTAAGCCTTACCTTT & JK0435-0438 \\
JK046I & TTAGGTTTGGCTTGGCGAA & - \\
JK056I & ACTGGCAAGGCTAAGCTAA & JK0560-0559 \\
JK0985 & TTTTCTTGGTCTAACCTAA & JK0984-0979 \\
JKI470 & TACGTTTTGCGTAACCTCA & - \\
JKI778 & TTAGCTTAGGTTTACCTAT & -
\end{tabular}

DNA binding protein membrane protein iron $A B C$ transport system $A B C$ transport system collagen binding protein iron $A B C$ transport system Fe-S cluster assembly system secreted protein enterochelin esterase

-
-
cg0466, DIP0625
-
-
DIP0I08
DIPI296
-
-


Table 2: Predicted DtxR binding sites in corynebacterial genome sequences (Continued)

\begin{tabular}{|c|c|c|c|c|}
\hline JKI780 & ATAGGTTAGCCTACCCTTT & - & L-ornithine $\mathrm{N}_{5}$-oxygenase & - \\
\hline JKI783 & TTAGGTTATGCTAAGTTAA & JKI782-I78I & $A B C$ transporter & - \\
\hline JKI805 & TTAGGCAAGGGTAAGCTAA & - & iron utilization protein & - \\
\hline JKI809 & ACAGGTTAGGCTAACCAGA & JKI808-1806 & $A B C$ transport system & - \\
\hline $\mathrm{JK} 1812$ & TTAGGTAAGGCTACCATCA & - & solute binding protein & - \\
\hline JK 1815 & CAAGTGAAGGCTTACCTTA & JK1816-1818 & iron $A B C$ transport system & - \\
\hline $\mathrm{JK} 1819$ & CTTGATTAGCCTAACCTAA & JKI820-182I & siderophore synthesis system & - \\
\hline \multirow[t]{2}{*}{ JKI8872 } & TTAAGCAAGGCTTGACTAA & JKI886-I884 & iron $A B C$ transport system & cg0926, CE088I \\
\hline & TAAGGTTCGGCTAACTGTA & & & \\
\hline JK1934 & GCAGGTGACGCTAACCTGT & - & HTH_3-family regulatory protein & - \\
\hline JK 1979 & GTAGCCTAGCCTTACCTAA & - & ornithine cyclodeaminase & - \\
\hline JK1983 & GAAGGTGTGGCTAACCTAA & JK I984-1985 & iron $A B C$ transport system & - \\
\hline
\end{tabular}

I C. diphtheriae genes described previously as part of the DtxR regulon $[14,15]$

2 Two DtxR binding sites were identified in front of the coding region.

${ }^{3} \mathrm{~A}$ single DtxR binding site is involved most likely in regulation of adjacent coding regions located on the opposite DNA strand [14, 15].

constructed within the coding region of the $d t x R$ gene, resulting in the mutant strain C. glutamicum IB2103 that was unable to grow in CGXII minimal medium under high-iron conditions. However, when the $d t x R$ mutant $C$. glutamicum IB2103 was cultivated in low-iron CGXII medium, it revealed the same growth behavior as the wild-type control. These experiments showed that the $d t x R$ gene is dispensable in C. glutamicum under specific culture conditions, as it was previously demonstrated for the orthologous regulatory genes $d t x R, d m d R 1$ and $i d e R$ of C. diphtheriae, Streptomyces coelicolor and Mycobacterium smegmatis, respectively [33-35]. On the other hand, the ideR gene of Mycobacterium tuberculosis can be inactivated only in the presence of a second functional copy of the gene or when a second-site suppressor mutation alleviates the lethal effects of ideR inactivation, making ideR an essential gene in this bacterial species [36].

As observed with the defined $d t x R$ mutant strain $C$. glutamicum IB2103, growth of the $d t x R$ transposon mutant C7 $(\beta) 18.5$ of $C$. diphtheriae was dependent on the amount of iron that was added to the culture medium [33]. The C7 $(\beta) 18.5$ mutant of $C$. diphtheriae exhibited an extended lag phase and slower exponential growth in low-iron medium when compared with the parental C7 $(\beta)$ wildtype strain. Moreover, the C7( $\beta$ )18.5 mutant grew only poorly in high-iron medium when compared with a control medium containing no additional iron sources, and it was more-easily killed by exposure to high-iron conditions and $\mathrm{H}_{2} \mathrm{O}_{2}$ than was the parental strain [33]. Since the DtxR protein apparently regulates the expression of iron uptake systems, it might also be involved in protecting the cell from damage that is caused by high intracellular iron concentrations. Transcriptional deregulation of iron homeostasis favors the Fenton reaction, leading to the production of hydroxyl radicals that can damage all biological macromolecules [37]. Therefore, transcriptional regulation of iron metabolism by the DtxR protein in C. glutamicum is not only necessary for economic rea- sons but also to avoid inevitable iron toxicity. In E. coli, iron homeostasis and oxidative stress response are closely interconnected and strictly controlled by the transcriptional regulator Fur [38]. Inactivation of the fur gene enhanced the sensitivity of the cell to redox stress, a physiological effect that can be reversed by iron chelation, by inhibiting ferric iron transport or by enhancing the iron storage capacity of the cell [37].

The $d t x R$ mutant C. glutamicum IB2103 was further on used to compare the genome-wide expression pattern with that of the wild-type strain by DNA microarray hybridizations. In principle, inactivation of a gene encoding a repressor results in constitutive expression of those genes that are directly regulated by the respective protein. Therefore, comparative DNA microarray hybridizations are typically carried out in such a way that the relevant genes of the wild-type control are repressed and those of the mutant strain are de-repressed [39]. Since the $d t x R$ mutant C. glutamicum IB2103 grew only in low-iron medium containing a trace amout of iron, the genes of the DtxR regulon are apparently de-repressed in both the mutant strain and the wild-type control. To detect differential gene expression in C. glutamicum IB2103, we applied an alternative experimental setup by the subsequent addition of an appropriate amount of iron to lowiron growth medium. Indeed, the DtxR repressor switched off the expression of its target genes in the wild-type strain, whereas the target genes were further on expressed in the $d t x R$ mutant. This physiological effect was detectable on a global scale by DNA microarray experiments and enabled the screening for differentially expressed genes that were later on assigned to the DtxR regulon of $C$. glutamicum. In addition to genes belonging to the DtxR regulon, the DNA microarray hybridization identified numerous coding regions whose expression was positively or negatively influenced in response to the iron stimulus. These genes are considered to be subject to indirect regulation by iron and are apparently not part of the 
DtxR regulon of C. glutamicum since they lack DtxR binding sites in their upstream regions. Investigating the physiological role of these genes in the cellular response to the subsequent addition of iron might eventually allow a better understanding of the molecular mechanisms used by C. glutamicum to counter high-iron conditions.

Furthermore, the combination of bioinformatics predictions and DNA band shift assays resulted in the identification of DtxR binding sites within the upstream region of 31 genes and gene clusters, suggesting that at least 64 genes are under direct transcriptional control by DtxR in C. glutamicum. For a closer examination of the identified DtxR binding sites, transcriptional start sites of four differentially expressed genes were determined and the corresponding promoters were mapped. Three DtxR binding sites were found to overlap the deduced promoter regions, suggesting that DtxR acts as transcriptional repressor by blocking RNA polymerase binding and thus preventing expression of the respective genes [25]. Similar results were reported upon promoter mapping and localization of DtxR binding sites in C. diphtheriae [40] and of IdeR binding sites in M. smegmatis and M. tuberculosis [41,42]. On the other hand, the DtxR binding sites of $c g 2782$, $c g 3327$ and $c g 0445$ were located upstream of the deduced -35 promoter region. Since the respective genes showed a decreased expression in C. glutamicum IB2103 during DNA microarray hybridization, this location is more consistent with an activating function of the corresponding transcriptional regulator [25]. In general, transcriptional regulators activate the expression of genes in such a way that they facilitate interaction of the RNA polymerase with the respective promoters. However, the large distance of the DtxR binding site to the -35 promoter region of the cg0445 gene cluster that encodes the iron-containing succinate dehydrogenase complex of C. glutamicum suggests an alternative activation mechanism. In this context it is noteworthy that the cg0445 gene cluster is also under direct transcriptional control by the RipA repressor [23], a member of the AraC-family of DNA-binding transcriptional regulators [7]. Some members of the AraC protein family fulfill their regulatory function by using two DNA binding sites and a DNA looping mechanism to control gene expression [43]. The DtxR binding site in front of cg0445 is located directly adjacent to the RipA binding site A, and DtxR binding might therefore interfere with RipA binding to exert its regulatory function. Since expression of the ripA gene is also controlled by DtxR, the corresponding network topology of the DtxR regulon represents a coherent feed-forward loop of type 4 , in which the direct connection to the target gene is activating and the indirect connections are both repressing [44]. In such a way environmental input signals can be integrated into the transcriptional regulatory network at different levels of regulatory hierarchy to control expression of the succinate dehydrogenase complex.

In addition to the cg0445 gene cluster, the $d p s$ (cg3327) and $f t n$ (cg2782) genes showed a decreased expression in the $d t x R$ mutant C. glutamicum IB2103. Dps-like proteins may function either as anti-redox agents or iron storage proteins, whereas ferritins act primarily in iron storage [13]. These data indicated that the DtxR protein can exert a regulatory role as positive modulator of expression of genes that are involved in iron storage and DNA protection. This mechanism of transcriptional regulation is reasonable since the iron storage and protection genes are not expressed under low-iron conditions, whereas both, the iron storage capacity of the cell and the protection of DNA, increase under high-iron conditions by activating the respective genes. In $M$. tuberculosis, expression of the iron storage genes $b f r A$ and $b f r B$, encoding a bacterioferritin and a ferritin-like protein, is induced also by iron and IdeR $[36,42]$. Binding of IdeR to the regulatory region of $b f r A$ indicated that the gene is transcribed from a promoter that is activated by iron and binding of IdeR, since induction of $b f r A$ gene expression was detected in the wild-type but not in an ideR mutant strain. The transcriptional control of iron storage in E. coli was also shown to be positively regulated by iron but no direct interaction of Fur with the regulatory region of the $b f r A$ and $f t n$ genes has been observed $[45,46]$.

The comparative content analysis of DtxR binding sites in four corynebacterial genome sequences provided further insights into the topology of the DtxR regulon of $C$. glutamicum. The deduced consensus sequences of DtxR binding sites are not only very similar among the corynebacterial species but also resemble IdeR and DmdR1 binding sites that were detected in $M$. tuberculosis and $S$. coelicolor, respectively $[42,47]$. Consequently, DtxR-like regulatory proteins utilize conserved recognition signals in different actinobacteria, as is the situation with DNA binding sites of the Fur repressor in gamma-proteobacteria [38]. On the other hand, the comparative content analysis revealed that most of the DtxR-regulated genes are species-specific in the four sequenced corynebacteria, indicating that a wide variety of genetic information is used in the individual species to provide an effective iron homeostasis. Varying genetic information can be gained for instance by horizontal gene transfer, as suggested for the $C$. jeikeium genome that contains large sets of DtxRregulated iron acquisition genes on mobile genetic elements [10]. As iron metabolism is closely connected to iron toxicity, any additional genetic information regarding iron metabolism has to be integrated into the preexisting DtxR regulon to avoid detrimental consequences for the bacterial cell. Only in case of similar DNA binding sites being present in the regulatory region of the respec- 
A)

\section{C. glutamicum}

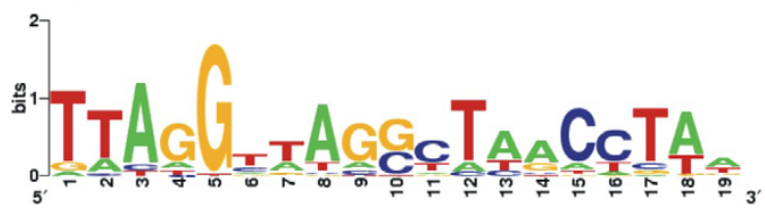

C. efficiens

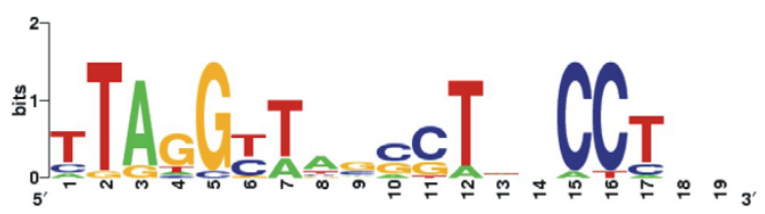

C. diphtheriae

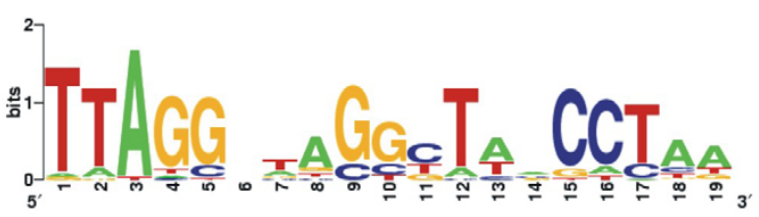

\section{C. jeikeium}

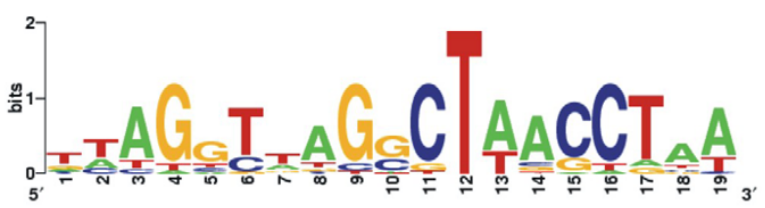

B)
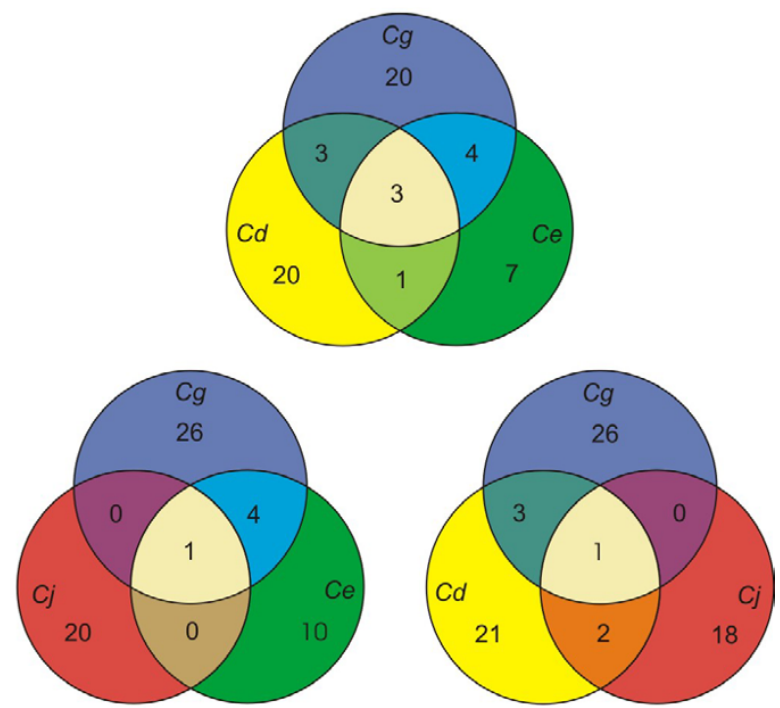

Figure 6

Comparative analysis of the DtxR regulons of sequenced corynebacterial species. (A) Deduced consensus sequences of DtxR binding sites represented by sequence logos. (B) Comparative content analysis of $D$ txR binding sites belonging to the DtxR regulon. The Venn diagrams show the number of shared and species-specific DtxR binding sites among the genomes of $C$. glutamicum ( $(\mathrm{g})$, C. efficiens $(C e)$, C. diphtheriae $(C d)$, and $C$. jeikeium $(C j)$.

tive genes, it is generally ensured that the genes fall under direct regulation by the DtxR protein and that the bacterium can benefit from the acquired genetic information. The close functional relationship between DNA binding sites of at least DtxR and IdeR is indeed apparent from the observation that the regulatory proteins can interact with operators of the cognate regulons in either corynebacteria or mycobacteria [48].

\section{Conclusion}

In summary, the presented experimental work adds considerably to our currrent understanding of the transcriptional regulatory network of $C$. glutamicum genes that are controlled by the diphtheria toxin repressor homolog DtxR and of the response of this bacterium to changing environmental iron levels. The results demonstrate that DtxR acts as a dual transcriptional regulator with a major role in controlling the expression of genes involved in iron metabolism. The DtxR protein exerts its dual regula- tory function as repressor of genes participating in iron uptake and iron utilization and as activator of genes responsible for iron storage and DNA protection. Moreover, the data suggest that the DtxR protein acts as global regulator by controlling the expression of other regulatory proteins that might take care of an iron-dependent regulation of a broader transcriptional network of C. glutamicum genes.

\section{Methods}

\section{Bacterial strains and growth conditions}

Wild-type strain C. glutamicum ATCC 13032 (American Type Culture Collection, Manassas, VA) was used to characterize the DtxR regulon. C. glutamicum strains were routinely grown at $30^{\circ} \mathrm{C}$ in Luria-Bertani medium [49]. Growth of C. glutamicum strains in CGXII minimal medium [50] containing $30 \mathrm{mg} / \mathrm{l}$ protocatechuic acid was monitored in time intervals of $1 \mathrm{~h}$ with the nephelometer Nephelostar Galaxy (BMG Laboratories, Offenburg, Ger- 
many). Standard CGXII minimal medium $(10 \mathrm{mg} / \mathrm{l}$ $\left.\mathrm{FeSO}_{4}\right)$ and low-iron CGXII medium $\left(0 \mathrm{mg} / \mathrm{l} \mathrm{FeSO}_{4}\right)$ were used for growth assays [33]. Growth of shaking flask cultures was monitored by measuring the optical density at $600 \mathrm{~nm}$ with an Eppendorf BioPhotometer. E. coli DH5 $\alpha$ MCR was used for standard cloning procedures and grown at $37^{\circ} \mathrm{C}$ in Luria-Bertani medium [49] supplemented with $2 \mathrm{~g} / \mathrm{l}$ glucose. Selection for the presence of plasmids was performed with kanamycin $(50 \mu \mathrm{g} / \mathrm{ml}$ for $E$. coli and $25 \mu \mathrm{g} / \mathrm{ml}$ for C. glutamicum). Isopropyl beta-Dthiogalactoside (IPTG) was used to induce $d t x R$ expression by the $P_{\text {trc }}$ promoter of pEC-XK99E [22].

\section{DNA isolation, manipulation and transfer}

Vector DNA was prepared from E. coli cells by an alkaline lysis technique using the QIAprep Spin Miniprep Kit (Qiagen, Hilden, Germany). Chromosomal DNA of $C$. glutamicum was prepared as described previously [51]. Modification of DNA, analysis by agarose gel electrophoresis and ligation were performed by standard procedures [49]. Transformation of E. coli and C. glutamicum cells was performed by electroporation [52,53].

\section{PCR techniques and dtx $R$ mutant construction}

PCR experiments were carried out with a PTC-100 thermocycler (MJ Research, Watertown, MA), Pwo DNA polymerase (Roche Diagnostics, Mannheim, Germany) and chromosomal C. glutamicum DNA as template. PCR products were purified by using the PCR Purification Spin Kit (Qiagen). Oligonucleotides used for PCR amplification were purchased from Operon Biotechnologies (Cologne, Germany). The gene SOEing method [54] was applied to construct a pK18mobsacB derivative that is suitable to perform an allelic exchange of the $d t x R$ gene in the chromosome of C. glutamicum ATCC 13032 [19]. The primers used were cg2103del1 (GATCTAGAATTCCCAAGGCGTGAGATGACAG), cg2103del2 (GAGCACGCAGAGGAACAAT),

cg2103del3

(ATTGTTCCTCTGCGTGCTCTCAAGCAGATGAGCCTGAT), and cg2103del4 (GATCTAGGATCCTTCTACGCGGACTGCATGT). The DNA fragment was digested with EcoRI and BamHI and cloned into the vector pK18mobsacB. The resulting plasmid pIB2103 carries a modified $d t x R$ gene that is specified by a defined deletion of 338 nucleotides. Gene replacement in the chromosome of C. glutamicum ATCC 13032 resulted in the $d t x R$ mutant strain C. glutamicum IB2103. For genetic complementation of mutant strain C. glutamicum IB2103, the $d t x R$ coding region was amplified by PCR with the primer pair compl1 (GATCTAGAATTCAAAGGAGGACAACCATGAAGGATCTGGTCGATAC) and compl2 (GATCTAGGATCCGTGTGTTAGCCCTCAACC). The PCR product was digested with EcoRI and BamH and cloned into the compatible sites of the IPTG-inducible expression vector pEC-XK99E [22]. The resulting plasmid pIB4000 was transferred into C. glutamicum ATCC 13032 and C. glutamicum IB2103 by electrotransformation.

Total RNA preparation and DNA microarray hybridization For the preparation of total RNA, C. glutamicum cultures were grown in minimal medium CGXII. Approximately 1 $\times 10^{9}$ cells from exponentially growing cultures were harvested by centrifugation with $11,000 \mathrm{~g}$ for $15 \mathrm{~s}$ and subsequently transferred into liquid nitrogen. RNA isolation, cDNA synthesis, labeling of probes, and DNA microarray hybridization were performed as described previously [20]. The experiments were carried out in duplicate using label swapping. Normalization and evaluation of data was accomplished by the EMMA microarray data analysis software using a $m$-value cut-off of \pm 1 , which corresponds to relative expression changes equal or greater than twofold [20]. Since each DNA microarray contains four replicates per gene, a total number of eight spots per gene was available for calculating differential gene expression.

\section{Bioinformatics tools for DtxR binding site prediction}

The annotated version of the C. glutamicum ATCC 13032 genome sequence [6] was used to perform a genome-wide screening for putative DtxR binding sites. The search was accomplished by Hidden Markov model (HMM) analysis using the HMMER software package [55]. A set of predicted DtxR binding sites was aligned by means of the CLUSTAL X program [21], and the resulting alignment was used to create a HMM by using the HMMBUILD module. The calculated HMM profile along with the HMMSEARCH module was applied to screen the $C$. glutamicum genome sequence for the presence of DtxR binding sites. The genomic positions of the resulting hits were correlated with coding sequences that revealed differential expression in the $d t x R$ mutant when compared with the wild-type strain by DNA microarray hybridization. The experimentally verified DtxR binding sites of $C$. glutamicum were aligned with the CLUSTAL X program and used to generate a HMM profile for an iterative screening of the genome sequences of C. efficiens [8], C. diphtheriae [9] and C. jeikeium [10].

\section{Real-time reverse transcription (RT)-PCR}

Purified total RNA of C. glutamicum cultures was used for real-time RT-PCR experiments with the LightCycler instrument (Roche Diagnostics) and the Quanti-Tect SYBR Green RT-PCR Kit (Qiagen). Oligonucleotides used to measure relative gene expression were purchased from Operon Biotechnologies. Verification of RT-PCR products was performed by melting curve analysis. Differences in gene expression were determined by comparing the crossing points of two samples measured in duplicate. Crossing points were calculated by the LightCycler software (Roche Diagnostics). 


\section{Construction and purification of a His-tagged DtxR protein}

A PCR product fusing the coding region of the C. glutamicum $d t x R$ gene with a nucleotide sequence encoding a Cterminal His tag was generated by using the primer pair dtxR-His1 (GATCTAGAATTCAAAGGAGGACAACCATGAAGGATCTGGTCGATA) and dtxR-His2 (GATCTAGGATCCTTAATGGTGATGGTGATGGTGGCCCTCAACCTT TTCTAC). The PCR product was digested with EcoRI and BamHI and cloned into the IPTG-inducible expression vector pEC-XK99E [22]. The resulting plasmid pIB4001 was transferred to E. coli DH5 $\alpha \mathrm{MCR}$ and to C. glutamicum strains by electroporation. To isolate the His-tagged DtxR protein, E. coli DH5aMCR (pIB4001) was grown for $16 \mathrm{~h}$ in Luria-Bertani medium containing $50 \mu \mathrm{g} / \mathrm{ml}$ kanamycin and $0.1 \mathrm{mM}$ IPTG. Approximately $4 \times 10^{10}$ cells were harvested by centrifugation, resuspended in LEW buffer (50 $\mathrm{mM} \mathrm{NaH}{ }_{2} \mathrm{PO}_{4}, 300 \mathrm{mM} \mathrm{NaCl}$, one tablet of Roche Complete Mini protease inhibitors; $\mathrm{pH}$ 8.0) and transferred into a RiboLyser tube (Hybaid, Heidelberg, Germany). Cell disruption by means of the RiboLyser instrument was carried out with a speed rate of 6.5 and two time intervals of $30 \mathrm{~s}$. The His-tagged DtxR protein was purified from the protein crude extract with Protino Ni-TED 1000 packed columns (Macherey-Nagel, Düren, Germany) according to the manufacturer's instructions. After loading of the protein crude extract, the resin column was washed twice with $2 \mathrm{ml}$ LEW buffer. The His-tagged DtxR protein was eluted with $2.5 \mathrm{ml}$ LEW buffer containing $10 \mathrm{mM}$ imidazole and finally stored at $-20^{\circ} \mathrm{C}$. The resulting eluate was concentrated by using Amicon ultra-4 5000 MWCO centrifugal filter units (Millipore, Schwalbach, Germany) and subsequently analyzed by SDS-PAGE [53]. The protein concentration was determined with the Bio-Rad protein assay kit (Bio-Rad Laboratories, Munich, Germany). To verify the purification of the His-tagged DtxR protein, an aliqout of the eluate was enzymatically digested with modified trypsin (Promega, Mannheim, Germany) and the resulting peptide mass fingerprint was determined by MALDI-TOF mass spectrometry, applying an Ultraflex mass spectrometer (Bruker Daltonics, Bremen, Germany) and the MASCOT software.

\section{DNA band shift assays to characterize binding of the purified DtxR protein}

DNA band shift assays were performed with Cy3-labeled 40 mer oligonucleotides (Operon) that were annealed with corresponding complementary oligonucleotides to double-stranded DNA fragments by heating at $94^{\circ} \mathrm{C}$ for 5 min and annealing on ice for $15 \mathrm{~min}$. During band shift assays, $42 \mathrm{pmol}$ of purified His-tagged DtxR protein were mixed with 0.05 pmol DNA, $200 \mu \mathrm{M} \mathrm{CoCl}_{2}, 15 \%(\mathrm{v} / \mathrm{v})$ glycerol, and DtxR binding buffer $\left(20 \mathrm{mM} \mathrm{Na} \mathrm{HPO}_{4}, 50\right.$ $\mathrm{mM} \mathrm{NaCl}, 5 \mathrm{mM} \mathrm{MgCl} 2,2 \mathrm{nM}$ DTT, $10 \%$ (v/v) glycerol, $100 \mu \mathrm{g} / \mathrm{ml}$ BSA; pH 7.0 [56]), to get a total volume of 20 $\mu \mathrm{l}$. The assay was incubated at room temperature for 15 min and then separated with a $2 \%$ agarose gel (containing $\left.150 \mathrm{mM} \mathrm{CoCl}_{2}\right)$ prepared in gel buffer $\left(20 \mathrm{mM} \mathrm{Na}_{2} \mathrm{HPO}_{4}\right.$; $\mathrm{pH}$ 7.0). A voltage of $80 \mathrm{~V}$ was supplied for $1.5 \mathrm{~h}$. The agarose gel was scanned with a Typhoon 8600 Variable Mode Imager (Amersham Biosciences Europe, Freiburg, Germany). During displacement experiments, increasing concentrations of non-labeled competitor DNA (0.05 to 1 pmol) were added to the reaction batch.

\section{Identification of transcriptional start sites by the RACE method}

For the identification of transcriptional start sites, total RNA was isolated from C. glutamicum wild-type cultures grown in CGXII medium. RACE primers (18 mer oligonucleotides) binding 200 to 300 nucleotides downstream of the annotated translational starts of investigated genes along with $1 \mu \mathrm{g}$ of total RNA were used for cDNA synthesis. RACE primer sequences will be provided by the authors upon request. The resulting cDNA was modified and amplified by two additional PCRs using the 5'/3' RACE Kit second generation (Roche Diagnostics). PCR products were cloned into the pCR2.1-TOPO vector (Invitrogen, Karlsruhe, Germany) and transferred into competent E. coli TOP10 cells. DNA sequencing of cloned RACE products was performed by IIT Biotech (Bielefeld, Germany).

\section{Authors' contributions}

IB carried out the experimental work and drafted the manuscript. HW participated during real-time RT-PCR and RACE PCR experiments. ATH provided the DNA microarray. JK participated in data evaluation. AP conceived of the design of the figures and participated in supervision. AT conceived of the study and participated in co-ordination and supervision. All authors read and approved the final manuscript.

\section{Additional material}

\section{Additional file 1}

C. glutamicum genes transcriptionally up-regulated or down-regulated in the dtxR mutant IB2103 upon iron addition to the growth medium when compared to the wild-type ATCC 13032. Relevant molecular and expression data of all genes detected as differentially expressed in C. glutamicum IB2103 upon addition of iron to the growth medium

Click here for file

[http://www.biomedcentral.com/content/supplementary/1471-

2164-7-21-S1.pdf]

\section{Acknowledgements}

The authors thank Carola Eck for excellent technical assistance during MALDI-TOF mass spectrometry and Karina Brinkrolf for valuable discussions. 


\section{References}

I. Herrgard MJ, Covert MW, Palsson BO: Reconstruction of microbial transcriptional regulatory networks. Curr Opin Biotechnol 2004, I 5(I):70-77.

2. Tan K, Moreno-Hagelsieb G, Collado-Vides J, Stormo GD: A comparative genomics approach to prediction of new members of regulons. Genome Res 200 I, I I (4):566-584.

3. Perez-Rueda E, Collado-Vides J: The repertoire of DNA-binding transcriptional regulators in Escherichia coli K-I2. Nucleic Acids Res 2000, 28(8): | 838- I847.

4. Stormo GD, Tan K: Mining genome databases to identify and understand new gene regulatory systems. Curr Opin Microbiol 2002, 5(2): | 49-153.

5. Resendis-Antonio O, Freyre-Gonzalez JA, Menchaca-Mendez R, Gutierrez-Rios RM, Martinez-Antonio A, Avila-Sanchez C, Collado-Vides $\mathrm{J}:$ Modular analysis of the transcriptional regulatory network of E. coli. Trends Genet 2005, 2 I (I): I6-20.

6. Kalinowski J, Bathe B, Bartels D, Bischoff N, Bott M, Burkovski A, Dusch N, Eggeling L, Eikmanns BJ, Gaigalat L, Goesmann A, Hartmann M, Huthmacher K, Krämer R, Linke B, McHardy AC, Meyer F, Möckel B, Pfefferle W, Pühler A, Rey DA, Rückert C, Rupp O, Sahm H, Wendisch VF, Wiegräbe I, Tauch A: The complete Corynebacterium glutamicum ATCC 13032 genome sequence and its impact on the production of L-aspartate-derived amino acids and vitamins. J Biotechnol 2003, I 04( I-3):5-25.

7. Brune I, Brinkrolf K, Kalinowski J, Pühler A, Tauch A: The individual and common repertoire of DNA-binding transcriptional regulators of Corynebacterium glutamicum, Corynebacterium efficiens, Corynebacterium diphtheriae and Corynebacterium jeikeium deduced from the complete genome sequences. BMC Genomics 2005, 6(I):86.

8. Nishio $Y$, Nakamura $Y$, Kawarabayasi $Y$, Usuda $Y$, Kimura E, Sugimoto S, Matsui K, Yamagishi A, Kikuchi H, Ikeo K, Gojobori T: Comparative complete genome sequence analysis of the amino acid replacements responsible for the thermostability of Corynebacterium efficiens. Genome Res 2003, I3(7): I572-I579.

9. Cerdeno-Tarraga AM, Efstratiou A, Dover LG, Holden MT, Pallen M, Bentley SD, Besra GS, Churcher C, James KD, De Zoysa A, Chillingworth T, Cronin A, Dowd L, Feltwell T, Hamlin N, Holroyd S, Jagels K, Moule S, Quail MA, Rabbinowitsch E, Rutherford KM, Thomson NR, Unwin L, Whitehead S, Barrell BG, Parkhill J: The complete genome sequence and analysis of Corynebacterium diphtheriae NCTCI 3 I 29. Nucleic Acids Res 2003, 3 I (22):65 I 6-6523.

10. Tauch A, Kaiser O, Hain T, Goesmann A, Weisshaar B, Albersmeier A, Bekel T, Bischoff N, Brune I, Chakraborty T, Kalinowski J, Meyer F, Rupp O, Schneiker S, Viehoever P, Pühler A: Complete genome sequence and analysis of the multiresistant nosocomial pathogen Corynebacterium jeikeium K4I I, a lipid-requiring bacterium of the human skin flora. I Bacteriol 2005, I 87( 1 3):467|-4682

II. Oguiza JA, Tao X, Marcos AT, Martin JF, Murphy JR: Molecular cloning, DNA sequence analysis, and characterization of the Corynebacterium diphtheriae dtxR homolog from Brevibacterium lactofermentum. J Bacteriol 1995, I 77(2):465-467.

12. Boyd J, Oza MN, Murphy JR: Molecular cloning and DNA sequence analysis of a diphtheria tox iron-dependent regulatory element (dtxR) from Corynebacterium diphtheriae. Proc Natl Acad Sci U S A 1990, 87( I 5):5968-5972.

13. Andrews SC, Robinson AK, Rodriguez-Quinones F: Bacterial iron homeostasis. FEMS Microbiol Rev 2003, 27(2-3):2I 5-237.

14. Kunkle CA, Schmitt MP: Analysis of the Corynebacterium diphtheriae DtxR regulon: identification of a putative siderophore synthesis and transport system that is similar to the Yersinia high-pathogenicity island-encoded yersiniabactin synthesis and uptake system. J Bacteriol 2003 I 85(23):6826-6840.

15. Kunkle CA, Schmitt MP: Analysis of a DtxR-regulated iron transport and siderophore biosynthesis gene cluster in Corynebacterium diphtheriae. J Bacteriol 2005, I 87(2):422-433.

16. Qian Y, Lee JH, Holmes RK: Identification of a DtxR-regulated operon that is essential for siderophore-dependent iron uptake in Corynebacterium diphtheriae. J Bacteriol 2002, I 84( I 7):4846-4856

17. Schmitt MP: Utilization of host iron sources by Corynebacterium diphtheriae: identification of a gene whose product is homologous to eukaryotic heme oxygenases and is required for acquisition of iron from heme and hemoglobin. J Bacteriol 1997, I 79(3):838-845

18. Drazek ES, Hammack CA, Schmitt MP: Corynebacterium diphtheriae genes required for acquisition of iron from haemin and haemoglobin are homologous to $A B C$ haemin transporters. Mol Microbiol 2000, 36(I):68-84

19. Schäfer A, Tauch A, Jager W, Kalinowski J, Thierbach G, Pühler A Small mobilizable multi-purpose cloning vectors derived from the Escherichia coli plasmids pK I 8 and pKI 9: selection of defined deletions in the chromosome of Corynebacterium glutamicum. Gene 1994, I45(I):69-73.

20. Hüser AT, Becker A, Brune I, Dondrup M, Kalinowski ], Plassmeier J Pühler A, Wiegräbe I, Tauch A: Development of a Corynebacterium glutamicum DNA microarray and validation by genome-wide expression profiling during growth with propionate as carbon source. J Biotechnol 2003, I06(2-3):269-286.

21. Thompson JD, Gibson TJ, Plewniak F, Jeanmougin F, Higgins DG: The CLUSTAL $X$ windows interface: flexible strategies for multiple sequence alignment aided by quality analysis tools. Nucleic Acids Res 1997, 25(24):4876-4882.

22. Kirchner $O$, Tauch $A$ : Tools for genetic engineering in the amino acid-producing bacterium Corynebacterium glutamicum. J Biotechnol 2003, I 04( I-3):287-299.

23. Wennerhold J, Krug A, Bott M: The AraC-type regulator RipA represses aconitase and other iron proteins from Corynebacterium under iron limitation and is itself repressed by DtxR. J Biol Chem 2005, in press:

24. Patek M, Nesvera J, Guyonvarch A, Reyes O, Leblon G: Promoters of Corynebacterium glutamicum. J Biotechnol 2003, I 04(13):3I I-323.

25. Madan Babu M, Teichmann SA: Functional determinants of transcription factors in Escherichia coli: protein families and binding sites. Trends Genet 2003, I9(2):75-79.

26. Ermolaeva MD, Khalak HG, White O, Smith HO, Salzberg SL: Prediction of transcription terminators in bacterial genomes. $J$ Mol Biol 2000, 30 I (I):27-33

27. Schmitt MP: Transcription of the Corynebacterium diphtheriae hmuO gene is regulated by iron and heme. Infect Immun 1997, 65( I I):4634-464I.

28. Schäfer A, Schwarzer A, Kalinowski J, Pühler A: Cloning and characterization of a DNA region encoding a stress-sensitive restriction system from Corynebacterium glutamicum ATCC 13032 and analysis of its role in intergeneric conjugation with Escherichia coli. J Bacteriol 1994, I 76(23):7309-73 I9.

29. Rückert C, Koch DJ, Rey DA, Albersmeier A, Mormann S, Pühler A Kalinowski J: Functional genomics and expression analysis of the Corynebacterium glutamicum fpr2-cysIXHDNYZ gene cluster involved in assimilatory sulphate reduction. $B M C$ Genomics 2005, 6:121

30. Oram DM, Avdalovic A, Holmes RK: Analysis of genes that encode DtxR-like transcriptional regulators in pathogenic and saprophytic corynebacterial species. Infect Immun 2004, 72(4): $1885-1895$

31. Crooks GE, Hon G, Chandonia JM, Brenner SE: WebLogo: a sequence logo generator. Genome Res 2004, I 4(6): I I 88- I I 90.

32. Altschul SF, Madden TL, Schaffer AA, Zhang J, Zhang Z, Miller W, Lipman DJ: Gapped BLAST and PSI-BLAST: a new generation of protein database search programs. Nucleic Acids Res 1997, 25(I 7):3389-3402.

33. Oram DM, Avdalovic A, Holmes RK: Construction and characterization of transposon insertion mutations in Corynebacterium diphtheriae that affect expression of the diphtheria toxin repressor (DtxR). J Bacteriol 2002, I 84(20):5723-5732.

34. Flores FJ, Barreiro C, Coque J], Martin JF: Functional analysis of two divalent metal-dependent regulatory genes dmdRI and dmdR2 in Streptomyces coelicolor and proteome changes in deletion mutants. Febs / 2005, 272(3):725-735.

35. Dussurget O, Rodriguez M, Smith I: An ideR mutant of Mycobacterium smegmatis has derepressed siderophore production and an altered oxidative-stress response. Mol Microbiol 1996 , 22(3):535-544.

36. Rodriguez GM, Voskuil MI, Gold B, Schoolnik GK, Smith I: ideR, an essential gene in Mycobacterium tuberculosis: role of IdeR in iron-dependent gene expression, iron metabolism, and oxidative stress response. Infect Immun 2002, 70(7):337I-338I. 
37. Touati D: Iron and oxidative stress in bacteria. Arch Biochem Biophys 2000, 373(I): I-6.

38. Panina EM, Mironov AA, Gelfand MS: Comparative analysis of FUR regulons in gamma-proteobacteria. Nucleic Acids Res 200I, 29(24):5195-5206.

39. Rhodius VA, LaRossa RA: Uses and pitfalls of microarrays for studying transcriptional regulation. Curr Opin Microbiol 2003, 6(2): I I4-II9.

40. Lee JH, Wang T, Ault K, Liu J, Schmitt MP, Holmes RK: Identification and characterization of three new promoter/operators from Corynebacterium diphtheriae that are regulated by the diphtheria toxin repressor (DtxR) and iron. Infect Immun 1997, 65(1 0):4273-4280.

4I. Dussurget O, Timm J, Gomez M, Gold B, Yu S, Sabol SZ, Holmes RK, Jacobs WRJ, Smith I: Transcriptional control of the iron-responsive fxbA gene by the mycobacterial regulator IdeR. J Bacteriol I 999, I 8 I ( I I ):3402-3408.

42. Gold B, Rodriguez GM, Marras SA, Pentecost M, Smith I: The Mycobacterium tuberculosis IdeR is a dual functional regulator that controls transcription of genes involved in iron acquisition, iron storage and survival in macrophages. Mol Microbiol 200I, 42(3):85I-865.

43. Egan SM: Growing repertoire of AraC/XyIS activators. J Bacteriol 2002, I 84(20):5529-5532.

44. Mangan S, Alon U: Structure and function of the feed-forward loop network motif. Proc Natl Acad Sci U S A 2003, I 00(2 I): I | 980-I I985.

45. Stojiljkovic I, Baumler AJ, Hantke K: Fur regulon in gram-negative bacteria. Identification and characterization of new iron-regulated Escherichia coli genes by a fur titration assay. J Mol Biol 1994, 236(2):531-545.

46. Abdul-Tehrani H, Hudson AJ, Chang YS, Timms AR, Hawkins C, Williams JM, Harrison PM, Guest JR, Andrews SC: Ferritin mutants of Escherichia coli are iron deficient and growth impaired, and fur mutants are iron deficient. J Bacteriol 1999, I 8 I(5): | $415-1428$.

47. Flores FJ, Martin JF: Iron-regulatory proteins DmdR I and DmdR2 of Streptomyces coelicolor form two different DNA-protein complexes with iron boxes. Biochem J 2004, 380(Pt 2):497-503.

48. Schmitt MP, Predich M, Doukhan L, Smith I, Holmes RK: Characterization of an iron-dependent regulatory protein (IdeR) of Mycobacterium tuberculosis as a functional homolog of the diphtheria toxin repressor (DtxR) from Corynebacterium diphtheriae. Infect Immun I995, 63( I I ):4284-4289.

49. Sambrook J, Fritsch EF, Maniatis T: Molecular cloning: A laboratory manual. 2nd edition. Cold Spring Harbor New York, Cold Spring Harbor Laboratory Press ; 1989.

50. Keilhauer C, Eggeling L, Sahm H: Isoleucine synthesis in Corynebacterium glutamicum: molecular analysis of the ilvB-ilvNilvC operon. J Bacteriol 1993, I 75( I 7):5595-5603.

5I. Tauch A, Kassing F, Kalinowski J, Pühler A: The Corynebacterium xerosis composite transposon Tn5432 consists of two identical insertion sequences, designated ISI249, flanking the erythromycin resistance gene ermCX. Plasmid 1995, 34(2): ||9-|3|.

52. Tauch A, Kirchner O, Wehmeier L, Kalinowski J, Pühler A: Corynebacterium glutamicum DNA is subjected to methylationrestriction in Escherichia coli. FEMS Microbiol Lett 1994, I 23(3):343-347.

53. Tauch A, Kirchner O, Löffler B, Gotker S, Pühler A, Kalinowski J: Efficient electrotransformation of Corynebacterium diphtheriae with a mini-replicon derived from the Corynebacterium glutamicum plasmid pGAI. Curr Microbiol 2002, 45(5):362-367.

54. Horton RM, Hunt HD, Ho SN, Pullen JK, Pease LR: Engineering hybrid genes without the use of restriction enzymes: gene splicing by overlap extension. Gene 1989, 77(I):6I-68.

55. HMMER profile HMMs for protein sequence analysis. http:// hmmer.wustl.edul.

56. Schmitt MP, Twiddy EM, Holmes RK: Purification and characterization of the diphtheria toxin repressor. Proc Natl Acad Sci U S A 1992, 89(16):7576-7580.
Publish with Bio Med Central and every scientist can read your work free of charge

"BioMed Central will be the most significant development for disseminating the results of biomedical research in our lifetime. "

Sir Paul Nurse, Cancer Research UK

Your research papers will be:

- available free of charge to the entire biomedical community

- peer reviewed and published immediately upon acceptance

- cited in PubMed and archived on PubMed Central

- yours - you keep the copyright

Submit your manuscript here:

http://www.biomedcentral.com/info/publishing_adv.asp
BiolMedcentral 